ARTICLE

DOI: $10.1038 /$ ncomms 8542 OPEN

\title{
Structural basis for cellobiose dehydrogenase action during oxidative cellulose degradation
}

Tien-Chye Tan ${ }^{1,2,}$, Daniel Kracher ${ }^{3, \star}$, Rosaria Gandini ${ }^{1,2}$, Christoph Sygmund ${ }^{3}$, Roman Kittl ${ }^{3}$, Dietmar Haltrich ${ }^{3}$, B. Martin Hällberg ${ }^{4,5}$, Roland Ludwig ${ }^{3}$ \& Christina Divne ${ }^{1,2}$

A new paradigm for cellulose depolymerization by fungi focuses on an oxidative mechanism involving cellobiose dehydrogenases $(\mathrm{CDH})$ and copper-dependent lytic polysaccharide monooxygenases (LPMO); however, mechanistic studies have been hampered by the lack of structural information regarding $\mathrm{CDH}$. $\mathrm{CDH}$ contains a haem-binding cytochrome (CYT) connected via a flexible linker to a flavin-dependent dehydrogenase $(\mathrm{DH})$. Electrons are generated from cellobiose oxidation catalysed by DH and shuttled via CYT to LPMO. Here we present structural analyses that provide a comprehensive picture of $\mathrm{CDH}$ conformers, which govern the electron transfer between redox centres. Using structure-based site-directed mutagenesis, rapid kinetics analysis and molecular docking, we demonstrate that flavin-tohaem interdomain electron transfer (IET) is enabled by a haem propionate group and that rapid IET requires a closed $\mathrm{CDH}$ state in which the propionate is tightly enfolded by $\mathrm{DH}$. Following haem reduction, CYT reduces LPMO to initiate oxygen activation at the copper centre and subsequent cellulose depolymerization.

\footnotetext{
${ }^{1}$ School of Biotechnology, KTH Royal Institute of Technology, AlbaNova University Center, Roslagstullsbacken 21, Stockholm S-10691, Sweden. ${ }^{2}$ Department of Medical Biochemistry and Biophysics, Karolinska Institutet, Scheelelaboratoriet, Scheeles väg 2, Stockholm S-17177, Sweden. ${ }^{3}$ Food Biotechnology Laboratory, Department of Food Science and Technology, Vienna Institute of Biotechnology (VIBT), BOKU_University of Natural Resources and Life Sciences, Muthgasse 18, Vienna A-1190, Austria. ${ }^{4}$ Department of Cell and Molecular Biology, Karolinska Institutet, Stockholm S-17177, Sweden. ${ }^{5}$ European Molecular Biology Laboratory, Hamburg Unit, Hamburg 22603, Germany; and Centre for Structural Systems Biology (CSSB), DESY-Campus, Hamburg 22603, Germany. * Shared first authorship. Correspondence and requests for materials should be addressed to R.L. (email: roland.ludwig@boku.ac.at) or to C.D. (email: divne@kth.se).
} 
T he need for renewable energy is increasing rapidly, and biofuel derived from plant matter is an attractive alternative to fossil-based fuels. However, the bioconversion of the major component of plant matter, cellulose, to low-molecular-weight saccharides is problematic and costly ${ }^{1,2}$. Despite decades of research on the molecular mechanisms of microbial cellulose depolymerization, a comprehensive picture of this elaborate biodegradation machinery has remained elusive. In nature, rot fungi and bacteria are primary factors in the recycling of lignocellulose-based biomass, and the efficient saccharification of cellulose has historically been assigned to a cascade of hydrolytic enzymes. An oxidative system was recently discovered in which extracellular flavocytochromes, that is, cellobiose dehydrogenases $(\mathrm{CDHs})^{3-7}$, cooperate with copperdependent lytic polysaccharide monooxygenases (LPMOs) ${ }^{8-13}$ to catalyse redox-mediated glycosidic bond cleavage in crystalline cellulose, hemicelluloses and starch. The CDH-LPMO system enhances the degradation efficiency of crystalline regions in cellulose by a previously unknown mechanism ${ }^{14-19}$.

$\mathrm{CDHs}$ are large flavocytochromes containing a haem $b$-binding cytochrome domain (CYT) connected by a long, flexible linker to a flavin adenine dinucleotide (FAD)-binding dehydrogenase domain $(\mathrm{DH})^{20}$. Class-I CDHs are produced by basidiomycetes and lack additional domains, whereas class-II CDHs occur in ascomycetes either with or without a type-1 carbohydrate-binding module (CBM), corresponding to classes IIA and IIB, respectively ${ }^{20,21}$. Despite the absence of a CBM, class-I CDHs bind strongly to the cellulose surface by an unknown mechanism ${ }^{22}$. The $\mathrm{DH}$ domain oxidizes cellobiose at the $\mathrm{C} 1$ position to cellobiono-1,5-lactone with reduction of FAD. The ensuing step involves inter-domain electron transfer (IET) from the reduced FAD to CYT haem $b$, presumably by single electrontransfer (ET) events, followed by ET from CYT to external electron acceptors ${ }^{20}$ such as LPMOs. LPMOs directly hydroxylate the crystalline polysaccharide substrate at $\mathrm{C} 1$ or $\mathrm{C} 4$ to produce the aldonic acid or the 4 -keto sugar, respectively ${ }^{10,17}$. The precise mechanism of the monooxygenation reaction is unknown but likely involves $\mathrm{C}-\mathrm{H}$ activation in which hydrogen abstraction and the formation of a radical oxygen species enable substrate hydroxylation, either by a superoxo mechanism ${ }^{15,17,23}$ or by an oxyl mechanism ${ }^{24}$.

As the linker between CYT and DH is long and flexible, attempts to crystallize full-length CDHs have been unsuccessful. For the $\mathrm{CDH}$ from the basidiomycete Phanerochaete chrysosporium $(P c \mathrm{CDH})$, crystal structures of the proteolytically generated CYT and DH fragments were determined separately ${ }^{25,26}$, but these studies did not provide experimental information regarding the physical association between CYT and DH. The lack of fulllength $\mathrm{CDH}$ structures has also hampered analysis of the possible mechanisms for ET between $\mathrm{CDH}$ and external electron acceptors such as LPMOs.

Here we report the crystal and solution structures of open and closed states of two fungal CDHs and one LPMO. The closed $\mathrm{CDH}$ structure reveals a shielded IET pathway from FAD in the DH domain to the haem $b$ in the CYT domain. Haem propionate- $\mathrm{A}$ in CYT enters the $\mathrm{DH}$ active site to interact with four side chains that we refer to as the propionate-docking site on DH. To evaluate whether this closed structure represents the relevant conformational state for productive IET, we performed rational site-directed mutagenesis of selected residues positioned between the FAD cofactor and the haem propionate- $\mathrm{A}$, as well as rapid-kinetics measurements, to probe IET between FAD and haem $b$ in the $\mathrm{CDH}$ variants. By applying small-angle X-ray scattering to deglycosylated and glycosylated forms of $\mathrm{CDH}$ in the absence and presence of an inhibitor, we demonstrated that both the open and closed $\mathrm{CDH}$ states are represented in solution.
We also show, for the first time, direct and rapid ET between CYT and LPMO, and that DH is unable to transfer electrons to LPMO. Our CDH crystal structures provide a necessary structural platform for further studies on the interaction mechanism between $\mathrm{CDH}$ and LPMO during cellulose depolymerization.

\section{Results}

Crystal structures of the closed and open states of $\mathrm{CDH}$. We screened a range of basidiomycete and ascomycete fungi and ultimately achieved successful crystallization and structure determination of two full-length $\mathrm{CDHs}$ from the ascomycetes Myriococcum thermophilum (MtCDH) and Neurospora crassa $(\mathrm{NcCDH})$ (Fig. 1), and of $\mathrm{LPMO}_{9 \mathrm{~F}}$ from N. crassa. The crystal structure of $M t \mathrm{CDH}$ was determined at $3.2 \AA$ and revealed a closed state in which the CYT domain is docked onto the DH domain in an arrangement that would allow efficient IET from FAD to haem $b$ (Fig. 2a). In the closed IET-competent state, the haem $b$ propionate-A stretches into the active-site pocket in $\mathrm{DH}$, where the propionate carboxyl group forms an anion-quadrupole interaction with the electropositive edge of the Trp295 benzene ring (Fig. 2a). Propionate-A engages in an ionic interaction with Arg698, which stabilizes the propionate in its ionized state. The haem $b$ propionate- $\mathrm{D}$ is folded away, and a hydrogen bond to Tyr99 in CYT prevents it from interacting directly with the $\mathrm{DH}$ active site. The closest edge-to-edge distance between haem $b$ and FAD is $9 \AA$. This distance is well within the $14-\AA$ limit for efficient electron transfer ${ }^{27}$ and is nearly identical to the haem-FMN distance of $9.7 \AA$ in flavocytochrome $b_{2}$, for which rapid IET has been observed ${ }^{28}$.

We observed that crystals of native, full-length $\mathrm{NcCDH}$ typically lacked interpretable density for the CYT domains. Data from one platinum-soaked crystal offered better-defined electron density for the CYT domains, which allowed us to model both $\mathrm{NcCDH}$ molecules in the asymmetric unit. The overall weak density for the CYT domains suggests significant flexibility in the linker regions. The two non-crystallographically (NCS)-related molecules are present as two 'open' states with different conformations of the flexible linkers and different relative orientations of the CYT and DH domains (Fig. 1). The haem $b$ is fully exposed and accessible in both open-state models.

The active site in $\mathrm{CDH}$ is accessible in the closed state. The active site of $\mathrm{CDH}$ has two glucosyl-binding subsites for cellobiose binding, subsite $\mathrm{B}$ (for binding site) and $\mathrm{C}$ (for catalytic site $)^{26,29}$. We determined the crystal structure of $M t \mathrm{DH}$ in complex with the substrate analogue cellobiono-1,5-lactam (CBLM). In this complex, Trp295 acts as a platform for the non-reducing end glucosyl unit in subsite B (Fig. 2b). Despite differences in active site side-chain composition (Supplementary Fig. 1), we observed that binding of CBLM in $M t \mathrm{DH}$ is nearly identical to that previously reported for the P. chrysosporium $\mathrm{DH}$ co-crystal structure ${ }^{29}$ (Supplementary Fig. 2). Superimposition of the structures of $M t C D H$ and $M t \mathrm{DH}-\mathrm{CBLM}$ with ligand-free $\mathrm{MtDH}$ revealed that only two active-site side chains differ in conformation: the indole ring of Trp295 tilts slightly 'upwards' with a maximum ring displacement of $1.4 \AA$, and Arg601 undergoes a conformational change involving $180^{\circ}$ rotations of $\chi^{3}$ and $\chi 4$ on ligand binding at site B (Fig. 2c). Comparison of $M t \mathrm{CDH}$ and $M t \mathrm{DH}-\mathrm{CBLM}$ revealed that neither the entry of propionate-A nor the binding of CBLM causes significant changes in the active site. Thus, the substrate and product can be spatially accommodated in the active site while CYT is docked onto DH in the closed state. A channel leads from the surface into the active site of the closed $\mathrm{MtCDH}$ molecule. The size of this channel is sufficient $(\sim 11 \times 12 \AA)$ to permit substrate entry and 
product exit while $M t \mathrm{CDH}$ remains in the closed IET-competent state (Supplementary Fig. 3).

Analysis of the FAD-haem $\boldsymbol{b}$ interaction by mutagenesis. We mutated positions in the substrate-binding region and at the CYT-DH interface (Fig. 3) to investigate the validity of the closed state of $M t \mathrm{CDH}$ for IET. The $M t \mathrm{CDH}$ structure indicates that the haem $b$ propionate-A in CYT interacts with four side chains in DH at the CYT-DH interface, that is, Trp295, Ser298, Met309 and Arg698, a region that we refer to as the propionate-docking site on DH. In the propionate-docking site, Trp295 performs an important role as a stacking platform for the non-reducing end glucosyl unit of the cellobiose substrate (Fig. 2b,c). In contrast, Ser298, Met309 and Arg698 do not interact with the substrate but with haem propionate-A (Fig. 3). The variants targeting the propionate-docking site included W295A, S298Q, M309A, M309R and R698S. Another set of mutations targeted side chains in the cellobiose-binding region that could potentially affect IET, that is, Asn292, Tyr549, Tyr619 and Asn700, by generating the single mutants N292S, Y549F, Y619Q and N700S.

Replacement of propionate-interacting residues in $\mathrm{DH}$. The reduction kinetics of FAD and haem $b$ indicated that mutations that target the propionate-docking site but not substrate binding (that is, S298Q, M309A, M309R, R698S) have little impact on FAD-reduction rates but large negative effects on haem $b$ reduction rates (Table 1). A notable exception is W295A, which shows similar performance as the wild-type enzyme. At the employed high cellobiose concentration, the apparent rate of FAD reduction is not compromised by the $\mathrm{W} 295 \mathrm{~A}$ mutation. The $12 \%$ higher haem $b$-reduction rate of this variant is most likely due to minor structural rearrangements. The barely affected rate of this mutation demonstrates that Trp295 is not essential for IET.

The side chain of Ser298 packs against the haem $b$ methyl group (attached to pyrrole ring $\mathrm{A}$ ), adjacent to propionate-A (Fig. 3). Replacing Ser298 with glutamine leads to a minor a

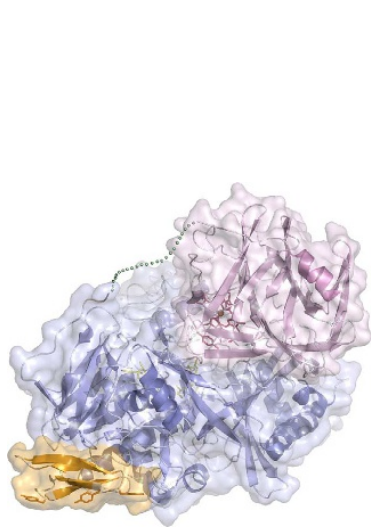

b

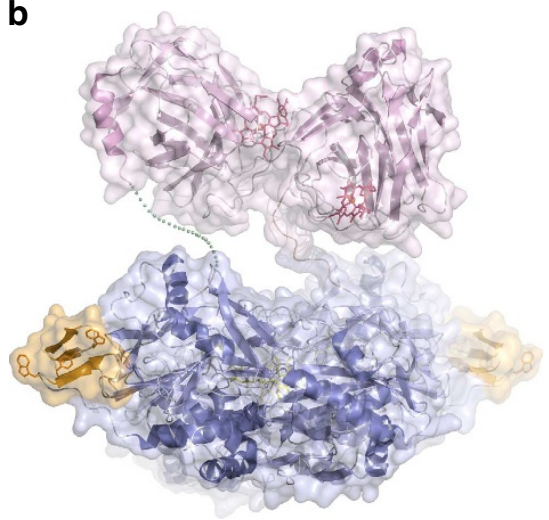

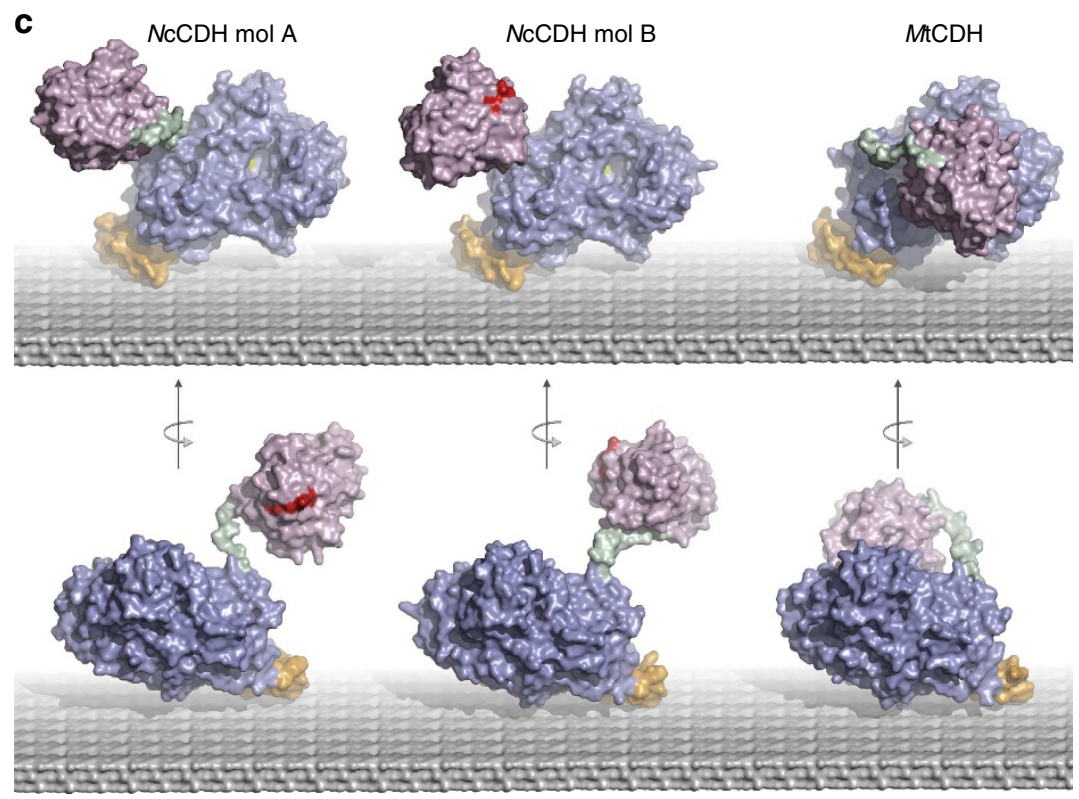

Figure 1 | Conformational states of $\mathbf{M t C D H}$ and $\mathbf{N c C D H}$. (a) $\mathrm{MtCDH}$ in the closed state shown as a ribbon drawing with a superimposed semitransparent surface. The missing residues 211-217 in the linker are shown as a green dotted line. Colour-coding: CYT domain (pink), DH domain (blue), CBM (orange), haem $b$ (red), FAD (yellow). (b) NcCDH with the same colouring scheme as in (a) showing the NCS-dimer of the asymmetric unit. The missing residues 206-217 in molecule B are shown as a green dotted line. (c) The crystal structure of NcCDH and MtCDH represented by molecular surfaces and modelled on an idealized crystalline cellulose surface. The molecules are oriented to optimize interaction of the cellulose-binding domain (orange) with the cellulose surface, and displayed in two views related by a $180^{\circ}$ rotation to visualize the relative positions of the CYT (pink), DH (blue) and linker (green) domains. The two NcCDH molecules $\mathrm{A}$ and $\mathrm{B}$ of the asymmetric unit have different linker conformations, revealing two unique open states. The haem $b$ group in the CYT domain is highlighted in red, and the entrance to the active site where the buried FAD molecule is visible (yellow) is indicated for $\mathrm{NcCDH}$ molecule B. For clarity, the missing residues in the linkers of $\mathrm{MtCDH}$ and $\mathrm{NcCDH}$ have been modelled and $\mathrm{N}$-linked glycans omitted. 


\section{a}

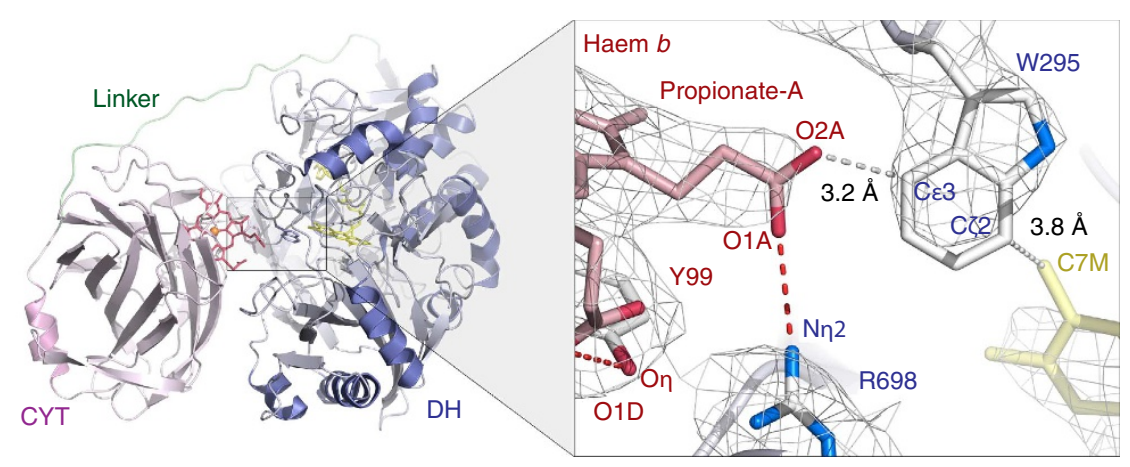

b

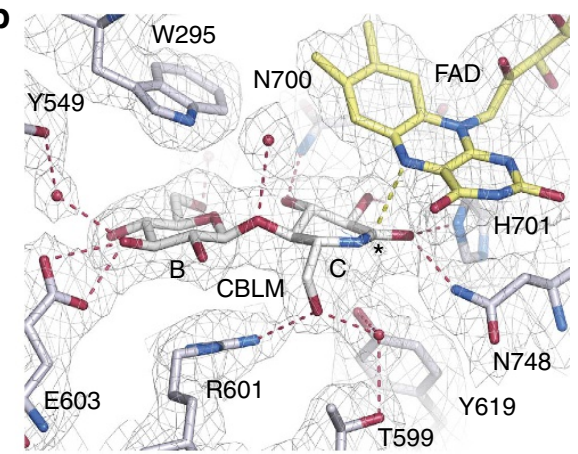

C

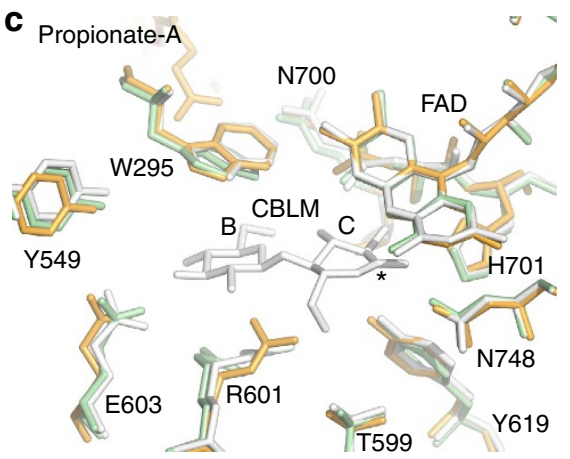

Figure 2 | Details of the closed state of MtCDH. (a) Ribbon drawing (left) of the closed IET-competent state of MtCDH showing the association of the CYT domain (pink) and the DH domain (blue). The inset (right) highlights the relative orientation of the haem $b$ in CYT (red) and the FAD (yellow) in DH (blue) with the $2 F_{O}-F_{c}$ electron density calculated at $3.2 \AA$ and contoured at $0.8 \sigma$. Dashed red lines represent interactions within hydrogen-bonding distance, and grey dashed lines the edge-to-edge distances for haem $b$-Trp295-FAD. (b) Binding of CBLM in the active site of $M t D H$ overlaid by a $2 F_{0}-F_{c}$ electron density contoured at 1.3 $\sigma$. The asterisk denotes the position in CBLM corresponding to the site of oxidation in cellobiose. The binding subsites are named $\mathrm{B}$ and $\mathrm{C}$. (c) Comparison of the active site in $\mathrm{MtCDH}$ (orange), MtDH-CBLM (white) and ligand-free MtDH (green). The catalytic amino acids His701 and Asn748 are positioned at the re-side of the flavin.

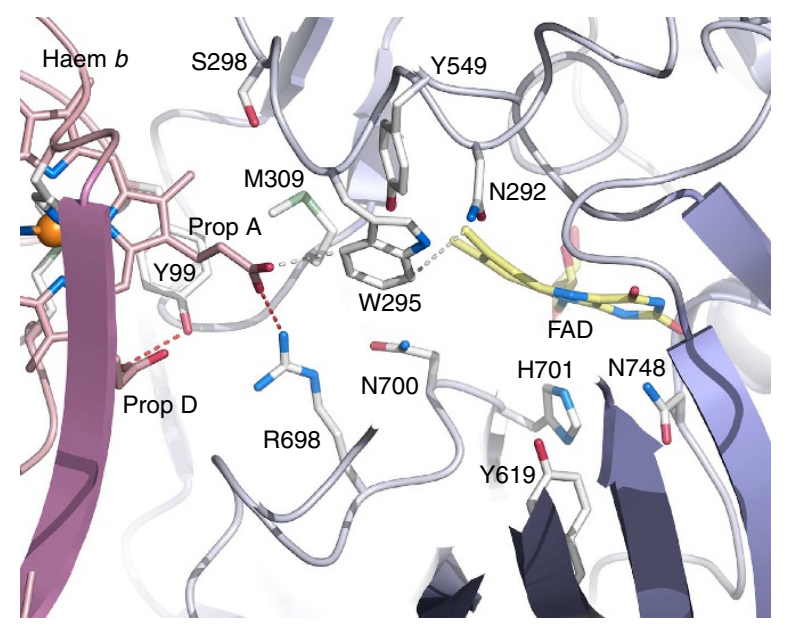

Figure 3 | Amino acids in MtCDH targeted for mutagenesis. Close-up of the interface between the cytochrome and dehydrogenase domains in $M t C D H$ showing the side chains targeted for mutagenesis to evaluate the haem $b$ propionate-A interactions in the closed state (Trp295, Ser298, Met309 and Arg698) and the substrate-binding region (Asn700, Asn292, Tyr619 and Tyr549).

decrease of $18 \%$ in the FAD-reduction rate, while the haem $b$ reduction rate decreases drastically by $88 \%$ (Table 1 ). The decrease in haem $b k_{\text {obs }}$ for S298Q can be rationalized by steric clashes between the longer glutamine side chain and haem pyrrole A (and with Gln175) in CYT that push propionate-A out from the propionate-docking site on $\mathrm{DH}$. In the wild-type

\begin{tabular}{|c|c|c|}
\hline MtCDH variant & FAD, $k_{\text {obs }}\left(s^{-1}\right)$ & haem $b, k_{\text {obs }}\left(s^{-1}\right)$ \\
\hline Wild type & $19.9 \pm 1.1$ & $0.76 \pm 0.01$ \\
\hline \multicolumn{3}{|c|}{ Propionate- $A$ interaction } \\
\hline W295A & $21.7 \pm 2.3$ & $0.86 \pm 0.01$ \\
\hline S298Q & $16.4 \pm 0.2$ & $0.090 \pm 0.007$ \\
\hline M309A & $6.9 \pm 0.6$ & $0.056 \pm 0.001$ \\
\hline M309R & $15.4 \pm 0.9$ & $0.088 \pm 0.006$ \\
\hline R698S & $19.2 \pm 1.7$ & $0.011 \pm 0.001$ \\
\hline \multicolumn{3}{|c|}{ Substrate-binding region } \\
\hline N292S & $23.9 \pm 0.3$ & $0.95 \pm 0.02$ \\
\hline Y549F & $18.8 \pm 1.1$ & $0.76 \pm 0.02$ \\
\hline Y619Q & $11.0 \pm 2.1$ & $0.38 \pm 0.01$ \\
\hline N700S & $26.1 \pm 1.1$ & $1.37 \pm 0.02$ \\
\hline
\end{tabular}

enzyme, Met309 forms van der Waals interactions with the aliphatic carbons of the propionate-A side chain and Tyr99 in CYT, as well as with Trp295, Arg698, Asn700 and the FAD 8-methyl group in DH (Fig. 3). Most, if not all, of these interactions would be eliminated in the M309A mutant, which also exhibits a drastic decrease in the haem $b$ reduction rate. Thus, Met309 is important for CYT-DH association, but interpretation of the effects of this mutation is complicated by the threefold reduction in the FAD-reduction rate, which indicates that the mutation has effects beyond the precise association of the functional domains. Another replacement at 
this position, M309R, maintains the aforementioned interactions with an unperturbed FAD-reduction rate while selectively interfering with propionate-A docking. The loss of IET in this mutant is attributable to the longer arginine side chain, which either pushes CYT away from the propionate-docking site on $\mathrm{DH}$ or locks the propionate-A carboxyl group in an ionic interaction. The guanidium group of Arg698 interacts directly with propionate-A, and replacing this side chain with serine abolishes haem $b$ reduction without affecting the FAD reduction rate, which is consistent with the observed structure of the closed state of $\mathrm{MtCDH}$.

Replacement of residues in the substrate-binding region. The side chain of Asn292 is positioned in subsite B, close to Trp295, but does not interact with either CYT or the haem $b$ group (Fig. 3). The FAD-reduction rate is increased by $20 \%$ for the $\mathrm{N} 292 \mathrm{~S}$ mutant at the high concentration of cellobiose $(25 \mathrm{mM})$, with a proportional increase in the rate of haem $b$ reduction (Table 1). Asn292 has no significant direct effect on the CYT-DH association or IET, which is also in agreement with the closed $\mathrm{MtCDH}$ structure. Another residue at the $\mathrm{DH}$ active-site entrance is Tyr549 (Fig. 3), which is located in the channel that runs across the CYT-DH interface. Here Tyr549 makes no direct contact with either the CYT domain, haem $b$ propionates, or substrate and is therefore not expected to affect either the CYT-DH association or IET. The unperturbed FAD and haem $b$ reduction rates of Y549F confirm that the Tyr549 hydroxyl group is not important for IET. The side chain of Tyr619 is located in subsite $\mathrm{C}$ in $\mathrm{DH}$, where it likely stabilizes the transition state during cellobiose oxidation ${ }^{29}$. We observed a 2-fold decrease in the $k_{\text {obs }}$ values for both FAD and haem $b$ reduction for Y619Q. The pronounced decrease in the FAD-reduction rate indicates that this variant is catalytically defective, which suggests that Tyr619 has functions other than promoting IET. The side chain of Asn700 packs against the dimethyl benzene nucleus of FAD, where it can form a hydrogen bond with the $\mathrm{O} 3$ hydroxyl of the reducing-end glucosyl of cellobiose in subsite C (Figs 2b and 3) and with Arg698. The variant N700S displays a 1.3-fold increase in the FAD-reduction rate and a disproportionally higher 1.8-fold increase in the haem $b$ reduction rate. The selective improvement in the IET rate may be due to an increase in the volume of the propionate-docking site caused by the substitution with the smaller serine residue, which may allow Arg698 to move closer to FAD, and consequently, bring propionate-A closer to the flavin.

Solution structures of $\mathbf{C D H}$. We used small-angle X-ray scattering (SAXS) analysis to investigate the conformational space of $\mathrm{CDH}$ in solution using the ensemble-optimization method (EOM), which employs a genetic algorithm for the selection of conformers from pools of randomly generated models ${ }^{30,31}$. SAXS was performed on glycosylated and deglycosylated $\mathrm{MtCDH}$ and $\mathrm{NcCDH}$ in the absence and presence of bound inhibitor (CBLM). Our results demonstrated that all $\mathrm{MtCDH}$ and $\mathrm{NcCDH}$ samples contain similar subsets of conformers in solution (Supplementary Figs 4 and 5). The conformer most similar to the closed state in the crystal structure of $\mathrm{MtCDH}$ is present in all samples (deglycosylated $\mathrm{MtCDH}$ cluster 5, deglycosylated $M t C D H / C B L M$ cluster 3, glycosylated $M t C D H$ cluster 1 and glycosylated $M t \mathrm{CDH} / \mathrm{CBLM}$ cluster 4 in Supplementary Fig. 4). In the presence of inhibitor, the ensemble of glycosylated $M t C D H$ exhibits fewer conformers in solution, with an open state resembling molecule $\mathrm{A}$ in the crystal structure of $\mathrm{NcCDH}$ as the most populated species (45\%) and a closed state resembling the $\mathrm{MtCDH}$ crystal structure as the second most populated conformer (27\%). Conformers resembling the closed state are also present in all $\mathrm{NcCDH}$ samples (deglycosylated $\mathrm{NcCDH}$ cluster 8, deglycosylated $\mathrm{NcCDH} / \mathrm{CBLM}$ cluster 7 , glycosylated $\mathrm{NcCDH}$ cluster 2 and 3, and glycosylated $N c C D H / C B L M$ cluster 1 and 4 in Supplementary Fig. 5). As with $\mathrm{MtCDH}$, glycosylated $\mathrm{NcCDH}$ exhibits an ensemble with fewer conformational clusters in the presence of inhibitor. We also confirmed that glycosylated and deglycosylated $\mathrm{MtCDH}$ and $\mathrm{NcCDH}$ were present in solution as monomers by performing chemical cross-linking, size-exclusion chromatography and native PAGE (data not shown).

Crystal structure of $\mathrm{NcLPMO}_{9 \mathrm{~F}} \cdot \mathrm{NcLPMO}_{9 \mathrm{~F}}$ primarily attacks crystalline cellulose and promotes, in combination with cellulases, faster and more complete surface degradation ${ }^{32}$. The structure of $N c \mathrm{LPMO}_{9 \mathrm{~F}}$ demonstrates that this LPMO shares the essential features of fungal LPMOs, including a $\beta$-sandwich fold and a catalytic surface-exposed copper centre (Fig. 4a) in which the copper is coordinated by the ligands His1, His72 and Tyr157 (Fig. 4b,c). Fungal LPMOs are typically post-translationally modified by protein glycosylation and methylation at the $\mathrm{N}$-terminal histidine (the function of this methylation is unknown). We determined that $\mathrm{NcLPMO}_{9 \mathrm{~F}}$ is expressed in Pichia pastoris as a 214-residue non-glycosylated protein. As observed for the fungal LPMO GH61D from Phanerochaete chrysosporium $^{33}$, the N-terminal histidine in $N_{c L P M O}$ is not methylated, in contrast to the methylation of other $N$. crassa LPMOs expressed using the natural fungal host ${ }^{15,23}$. Both NCS molecules in the $\mathrm{NcLPMO}_{9 \mathrm{~F}}$ crystal have copper ligated by four protein atoms in tetrahedral coordination and exhibit distorted octahedral coordination of the copper with mer$\left[\mathrm{MA}_{3} \mathrm{~B}_{3}\right]$ geometry together with external ligands (Fig. $4 \mathrm{~b}, \mathrm{c}$; Supplementary Fig. 6). In molecule A, two water molecules, one axial and one equatorial, satisfy the octahedral sphere (Fig. 4b; Supplementary Fig. 6a). In molecule B, both water molecules are replaced by the carboxylate oxygen atoms of Asp33 from molecule A (Fig. 4c; Supplementary Fig. 6b), which is similar to the coordination sphere observed in Streptomyces coelicolor $S c \mathrm{LPMO}_{10 \mathrm{~B}}$ where two oxygen atoms in an acetate molecule occupy the fourth equatorial and axial position on the solventfacing side of $\mathrm{Cu}(\mathrm{II})^{34}$. These observations emphasize the possibility of the 4 -coordinate $\mathrm{Cu}(\mathrm{II})$ in $N_{c L P M O}$ to accept one axial, and possibly also a fourth equatorial ligand (water or other).

The crystal structures of $N$. crassa $\mathrm{NcLPMO}_{9 \mathrm{D}}$ (PMO-2; PDB code 4EIR ${ }^{23}$; NCU01050; UniProt Q1K8B6) and $\mathrm{NcLPMO}_{9 \mathrm{M}}$ (PMO-3; PDB code 4EIS ${ }^{23}$; NCU07898; UniProt Q7SA19) have been determined at high resolution. While the overall fold of $N_{c L P M O}$ is very similar to those of $N_{c L P M O}$ (r.m.s.d. $1.45 \AA$ for $205 \mathrm{C} \alpha$ positions) and $N_{c L P M O}$ (r.m.s.d. $1.35 \AA$ for $189 \mathrm{C} \alpha$ positions), significant conformational changes are apparent in loop regions, including loops flanking the copper-binding site

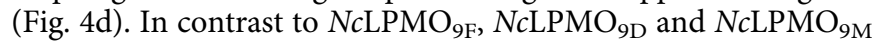
are glycosylated and have a methylated N-terminal histidine (Fig. 4e,f). Furthermore, the axial ligand occupied by water or

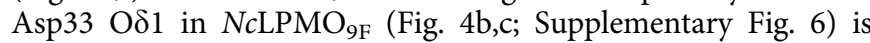
modelled as superoxide and peroxide in $N_{c L P M O}{ }_{9 \mathrm{D}}$ (Fig. $4 \mathrm{e}$ ) and $\mathrm{NcLPMO}_{9 \mathrm{M}}$ (Fig. 4f), respectively. Beyond the copper ligands, the amino-acid context differs in $\mathrm{NcLPMO}_{9 \mathrm{~F}}$ compared with $N c \mathrm{LPMO}_{9 \mathrm{D}}$ and $\mathrm{NcLPMO}_{9 \mathrm{M}}$ (Supplementary Fig. 7).

$N c C Y T$ but not $N c D H$ transfers electrons to $N_{c} \mathrm{LPMO}_{9 \mathrm{~F}}$ Next we performed rapid-kinetics experiments to confirm that direct ET occurs between $N c C Y T$ and $N_{c L P M O}$ (Fig. $4 \mathrm{~g}$ ). We observed very rapid $N c C Y T$-to- $N c L_{P M O}$ ET with a haem $b-k_{\text {obs }}$ value of $67.2 \pm 2.3 \mathrm{~s}^{-1}$. The re-oxidation rate of $\mathrm{NcCYT}$ by oxygen was 100,000 -fold slower $\left(0.0007 \mathrm{~s}^{-1}\right)$ than the rate for 
a

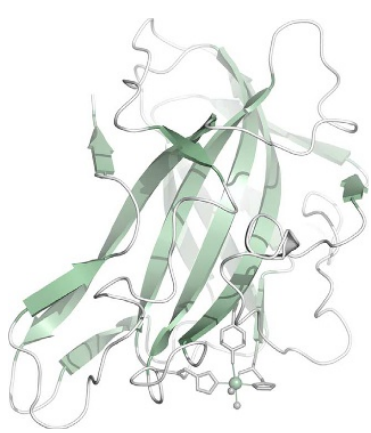

d

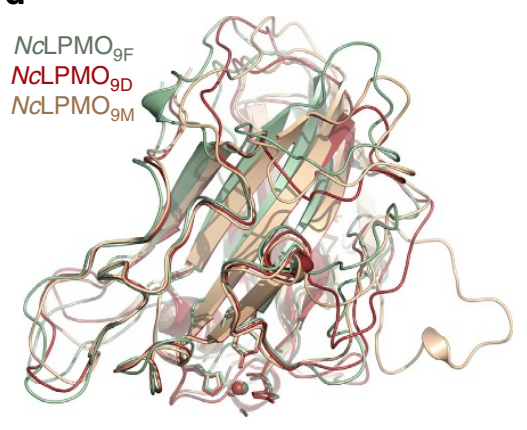

b

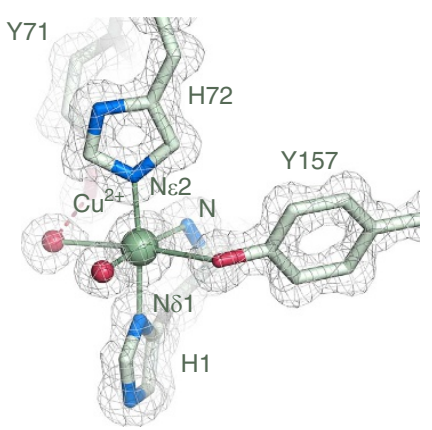

e

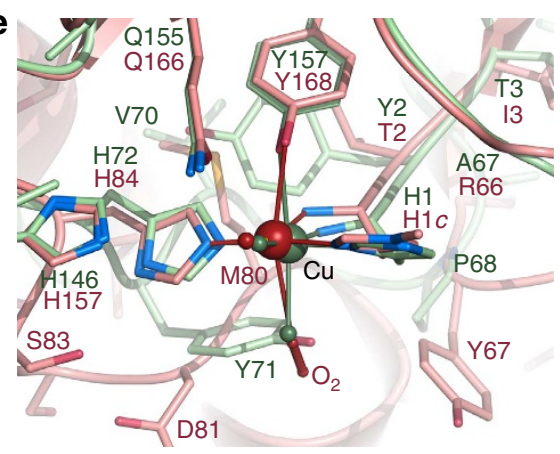

c

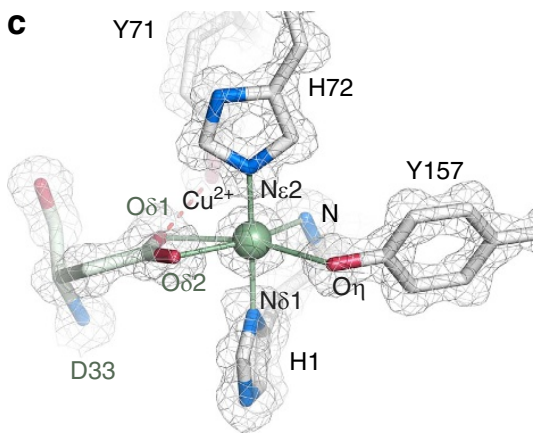

f

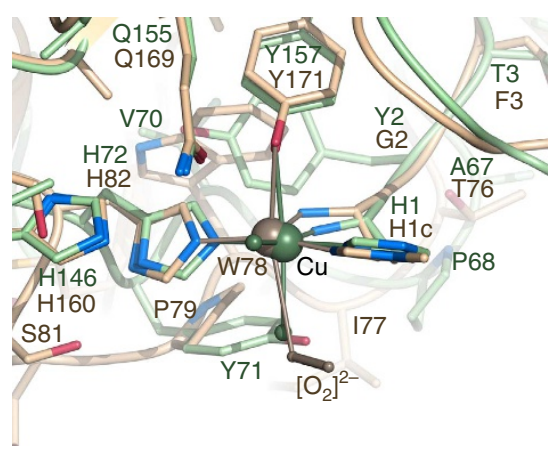

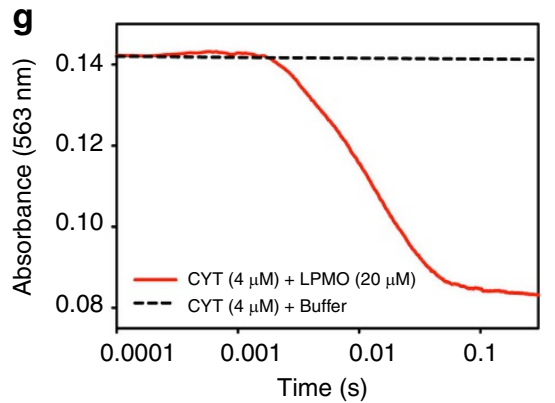

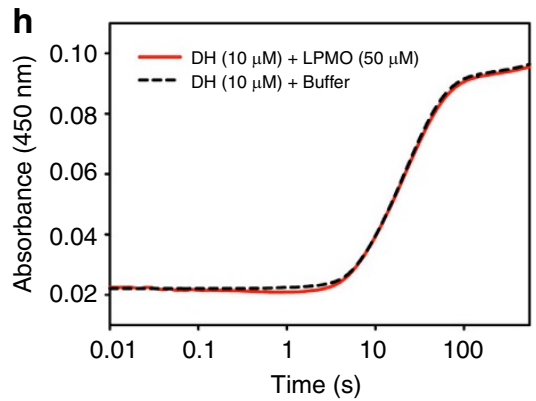

Figure 4 | Structure of $\mathbf{N C L P M O}_{9 \mathbf{F}}$ and interaction with $\mathbf{N c C Y T}$. (a) Overall structure of $\mathrm{NcLPMO}_{9 \mathrm{~F} .}$ (b) Distorted octahedral coordination for the copper in $\mathrm{NcLPMO}_{9 \mathrm{~F}}$ molecule A (green). The three nitrogen ligands provided by His1 and His72 are referred to as the histidine brace ${ }^{10}$. Coordination is satisfied by two water ligands (see Supplementary Fig. 6 for details). Overlay with $2 F_{O}-F_{c}$ electron density $(1.5 \sigma)$. (c) $\mathrm{Cu}(\mathrm{II})$ coordination in $N c L P M O_{9 F}$ molecule B (white). Octahedral coordination is satisfied by replacing the water ligands in (b) by two oxygen atoms from Asp33 (green) in the NCS-related A molecule. (d) Structural overlay of N. crassa LPMO $_{9 F}$ (green) with N. crassa PMO-2 (red; PDB code 4EIR ${ }^{23}$ ) and PMO-3 (beige; PDB code 4EIS ${ }^{23}$ ).

(e) Comparison of the copper centres in $\mathrm{NcLPMO}_{9 \mathrm{~F}}$ (green) and PMO-2. (f) Comparison of the copper centres in $\mathrm{NcLPMO}_{9 \mathrm{~F}}(\mathrm{green})$ and PMO-3. The residue $\mathrm{H} 1 \mathrm{c}$ represents a methylated $\mathrm{N}$-terminal histidine. (g) Interaction between $\mathrm{NcCYT}$ and $\mathrm{NCLPMO}_{9 \mathrm{~F}}$ displayed as an averaged kinetic trace (full line). The calculated haem re-oxidation rate from five repeated experiments $\left(k_{\mathrm{obs}}\right)$ is $67.2 \pm 2.3 \mathrm{~s}^{-1}$. For comparison, the haem re-oxidation by oxygen is shown as a dashed line. (h) The re-oxidation rates of the FAD cofactor of the $\mathrm{NcCDH}$ dehydrogenase domain $(10 \mu \mathrm{M})$ remains unchanged in the presence $\left(0.0442+/-0.0003 \mathrm{~s}^{-1}\right)$ and absence $\left(0.0444+/-0.0006 \mathrm{~s}^{-1}\right)$ of $50 \mu \mathrm{M} \mathrm{LPMO}$, showing that no reduction of the $\mathrm{NcLPMO}_{9 \mathrm{~F}} \mathrm{Cu}(\mathrm{II})$ centre takes place. The observed low rates are the result of a re-oxidation reaction with dissolved oxygen in the buffer.

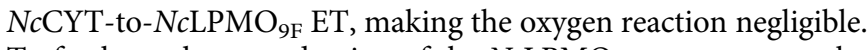
To further rule out reduction of the $\mathrm{NcLPMO}_{9 \mathrm{~F}}$ copper centre by the FAD cofactor in the $\mathrm{NcCDH}$ dehydrogenase, we performed a second stopped-flow experiment, which demonstrated conclusively that the $\mathrm{NcDH}$ domain alone is unable to reduce $\mathrm{Cu}(\mathrm{II})$ in $\mathrm{NcLPMO}_{9 \mathrm{~F}}$ (Fig. 4h). Our results demonstrate unequivocally that, in the N. crassa CDH IIA-LPMO 9 F pair, the reduced haem $b$ alone acts as the reductant of the $N c L P M O_{9 F}$ copper centre in vitro. The high ET rate observed in the study provides compelling evidence for LPMO as a physiologically relevant electron acceptor for the haem $b$ cytochrome.

To test the interaction of the NcCDH-NcLPMO $9 \mathrm{~F}$ pair, we performed automatic high ambiguity-driven biomolecular docking (HADDOCK). The program consistently returned interaction models where the haem $b$ propionate-A was docked close to the copper in $\mathrm{NcLPMO}_{9 \mathrm{~F}}$. The docking of solvated proteins does not consider the constrained accessibility of the copper site in cellulose-bound LPMO; however, in solution and when freely accessible, the copper site appears to be a favourable docking site for the haem $b$ propionate (Supplementary Fig. 8). Because no information concerning the precise copper-haem coordination geometry had been provided to the program, the precise details of the automatically generated CYT-LPMO interaction models cannot be evaluated; however, the interaction energies are favourable.

\section{Discussion}

The crystal and solution structures of two closely related class-II $\mathrm{CDHs}$ revealed pronounced flexibility of the linker between the CYT and DH domains to allow the efficient association of the haem $b$ with both the FAD electron donor (closed state) and 
external protein electron acceptors such as LPMO (open states). Using SAXS, we demonstrated that the conformers observed in the crystal structures are also present in solution and performed comprehensive mapping of accessible $\mathrm{CDH}$ conformers, including the closed state and a range of partially closed and open states. Moreover, our data demonstrate that similar $\mathrm{CDH}$ conformers are possible for glycosylated and deglycosylated samples and that the presence of an inhibitor reduces the number of accessible conformers in solution.

The crystal structure of the closed state of $M t \mathrm{CDH}$ offers a favourable association mode between the CYT and DH domains to permit efficient IET. The validity of the closed state is further emphasized by the drastically decreased IET rates of $M t C D H$ variants in which the interactions between haem $b$ propionate-A and DH at the CYT-DH interface have been disabled. Whereas the IET rates were diminished for mutations targeting the propionate-docking site, we observed no systematic effects on IET rates for the mutations targeting side chains in the substratebinding region occupying the space between the flavin and propionate-A. These results allow us to assign a fundamental role to the haem $b$ propionate-A in the IET mechanism. Haem propionate groups actively participate in ET events. For example, the use of mixed quantum mechanical/molecular mechanics calculations has provided direct evidence for the active involvement of haem-propionate groups in the ET pathway of ascorbate peroxidase and di-haem-c cytochrome $c$ peroxidase ${ }^{35}$. Our results, together with the low sequence conservation between ascomycete and basidiomycete $\mathrm{CDHs}$ (of the mutated residues, only Tyr619, Asn700 and Tyr549 are conserved in PcCDH; Supplementary Fig. 1), emphasize that efficient IET does not depend intimately on any one specific type of side chain but on the ability of CYT to associate with DH in a manner in which the relative position and distance between the haem propionate and FAD ensure IET.

In contrast to the intracellular enzyme flavocytochrome $b_{2}$, $\mathrm{CDH}$ is an extracellular flavocytochrome. A variety of twoelectron acceptors are generated during lignocellulose decomposition, for example, lignin-derived quinone compounds that would react rapidly with reduced FAD. How is specific FAD-haem $b$ IET ensured in this extracellular environment containing electron scavengers? If CYT docks with DH before substrate binding and remains docked during IET (and possibly after product departure), the IET path would be shielded both by the CYT-DH interface and by the bound product, thus preventing electron scavengers from accessing the reduced FAD before the haem $b$ is reduced and CYT is released. Indeed, various free one-electron acceptors such as $\mathrm{Fe}(\mathrm{III})$ and $\mathrm{Cu}(\mathrm{II})$ complexes are present in wood and could scavenge electrons from reduced CYT upon release from $\mathrm{DH}$. The surfaces near the channel entrance in $M t \mathrm{CDH}$ are rich in negatively charged residues that do not participate in complex formation (Supplementary Fig. 9a). It is tempting to speculate that their function may be to guard the entrance to allow carbohydrates to enter and exit, while metal ions are chelated and negatively charged molecular species are repelled. Overall, $\mathrm{NcCDH}$ has fewer negative surface residues but displays a similar trend of negative charges clustering near the channel entrance (Supplementary Fig. 9b).

In this work, we demonstrate that only the CYT haem $b$ of $\mathrm{NcCDH}$ can transfer electrons to $\mathrm{NcLPMO}_{9 \mathrm{~F}}$ and that $\mathrm{DH}$ alone is not an electron donor for LPMO. We expect this ET to manifest as a physical but not necessarily strong or long-lived protein complex. On the basis of global sequence conservation within the LPMO family, a conserved surface patch centred on ${ }^{218}$ Pro-Gly-Pro ${ }^{220}$ (numbering of $\mathrm{NcPMO}_{9 \mathrm{M}}$ ) has been suggested as an interaction site for $\mathrm{CDH}^{23}$. The patch is positioned $21 \AA$ from the copper centre, and its involvement assumes long-range electron tunnelling through the protein to reach the site of reduction. Such a scenario seems mechanistically reasonable for LPMO where, during catalysis, the copper-site is expected to be oriented towards the cellulose surface and therefore is inaccessible for a direct interaction with the redox centre in CYT. It is therefore surprising to find no conserved complementary surfaces on CYT. Rather, the haem $b$ propionate-A, which protrudes from the CYT surface and restricts surface complementarity between $\mathrm{CDH}$ and LPMO at the proposed interaction site, is the only absolutely conserved surface feature among different CDHs. Because CDH has to form a CYT-DH IET complex and has been observed to transfer electrons to a variety of LPMOs with different surface properties and even from different organisms, it is not surprising that the interacting interfaces display an overall low degree of surface complementarity. The results from ambiguity-driven biomolecular protein-protein docking suggest an alternative binding mode for LPMO when not bound to cellulose where the copper-binding surface provides the most favourable interaction site for CYT. However, it is not possible to evaluate the significance of such an interaction by automated molecular docking alone and mutational studies are needed to elucidate the in vivo interaction site.

At present, two principal LPMO mechanisms for glycosidic bond cleavage have been proposed. The first mechanism involves sequential $\mathrm{ET}^{17}$, in which an initial electron reduces $\mathrm{Cu}(\mathrm{II})$ to $\mathrm{Cu}(\mathrm{I})$, leading to the formation of a $\mathrm{Cu}(\mathrm{II})$-superoxo complex. A second electron is required after hydrogen abstraction from the substrate to cleave the $\mathrm{O}-\mathrm{O}$ bond in the $\mathrm{Cu}(\mathrm{II})$-hydroperoxo species, releasing water and generating a $\mathrm{Cu}(\mathrm{II})$-oxo radical that couples with the substrate radical and leads to the hydroxylation of the substrate. The second mechanism, which was suggested based on quantum mechanical calculations, proposes $\mathrm{C}-\mathrm{H}$ oxidation by a $\mathrm{Cu}(\mathrm{II})$-oxyl mechanism ${ }^{24}$ and argues that a $\mathrm{Cu}(\mathrm{II})$-oxyl complex is more reactive than the $\mathrm{Cu}(\mathrm{II})$-superoxo complex and that the $\mathrm{Cu}(\mathrm{II})$-oxyl species has a lower overall activation barrier than the $\mathrm{Cu}(\mathrm{II})$-superoxo species. This model hypothesizes two electron transfer events in series before LPMO reacts with cellulose. In both cases, hydroxylation at $\mathrm{C} 1$ or $\mathrm{C} 4$ destabilizes the glycosidic bond, and an elimination reaction leads to bond cleavage. Both models are compatible with one-electron transfer from CYT to LPMO, but the precise structural and mechanistic details of the CYT-LPMO interaction need further investigation.

In this work, we have presented for the first time the structural basis for electron transfer between FAD and haem $b$ in $\mathrm{CDH}$, and shown that the cytochrome alone is responsible for rapid electron transfer to LPMO. Our results provide the structural foundation towards a full molecular understanding of the role of the CDH-LPMO system in oxidative cellulose degradation by fungi.

\section{Methods}

Enzyme production. Cloning of all genes has been reported: Myriococcum thermophilum $\mathrm{CDH}^{36}$ (MtCDH IIA; gene $c d h$; UniProt A9XK88; the DH domain belongs to CAZy family AA3_1 and the CYT domain to CAZy family AA8 (ref. 37)), Neurospora crassa $\mathrm{CDH}$ IIA $^{21}$ ( $\mathrm{NcCDH}$; gene $c d h-1$; locus tag NCU00206; UniProt Q7RXM0; the DH domain belongs to CAZy family AA3_1 and the CYT domain to CAZy family AA8 (ref. 37)) and Neurospora crassa LPMO $\mathrm{NcLPMO}_{9 \mathrm{~F}}$ (ref. 38) (gene gh61-6; locus tag NCU03328; UniProt Q1K4Q1; CAZy family AA9).

The $M t \mathrm{CDH}$ variants were generated by a two-step mutagenesis approach using PCR and DpnI. The replacements included N292S, W295A, S298Q, M309A, M309R, Y549F, Y619Q, R698S and N700S. The mutations were confirmed by sequencing. Fed-batch fermentations of Pichia pastoris X-33 transformants were performed in a 7-litre bioreactor (MBR, Switzerland) with 3 litre starting volume following the Pichia Fermentation Process Guidelines of Invitrogen. After depletion of glycerol in the batch medium a 12 -h fed-batch phase was started with a constant feed of $50 \%$ glycerol containing $12 \mathrm{mll}^{-1} \mathrm{PTM}_{1}$ trace salts to increase biomass. For induction the feed was switched to pure methanol containing $12 \mathrm{mll}^{-1} \mathrm{PTM}_{1}$ trace salts and the cultivation temperature was reduced from 
30 to $25^{\circ} \mathrm{C}$. At the time the culture fully adapted to methanol the feed rate was automatically adjusted to keep the dissolved oxygen saturation constant at $4 \%$ at a constant air supply of $61 \mathrm{~min}^{-1}$ and a stirrer tip speed of $2.95 \mathrm{~m} \mathrm{~s}^{-1}$. Samples were taken regularly and wet biomass, protein concentration and enzyme activity were measured. Fermentation broths were harvested by centrifugation before the expression of the targeted enzymes stagnated. Wild type and mutant $\mathrm{CDHs}$ were expressed in concentrations from 50 to $400 \mathrm{mgl}^{-1}$, and the protein concentration of $N c \mathrm{LPMO}_{9 \mathrm{~F}}$ in the culture supernatant was $750 \mathrm{mgl}^{-1}$. Additional details have been reported elsewhere $\mathrm{e}^{36,38-40}$

Enzyme purification. $\mathrm{NcDH}, \mathrm{NcCYT}, \mathrm{NcCDH}, \mathrm{MtDH}$ and $\mathrm{MtCDH}$ variants were purified by a two-step chromatographic procedure starting with hydrophobic interaction chromatography using PHE-Sepharose FF (all chromatographic equipment and materials from GE Healthcare Biosciences). Proteins were applied in a $50 \mathrm{mM}$ sodium acetate buffer ( $\mathrm{pH} 5.5$ ) containing $20 \%$ ammonium sulfate (saturation) and eluted by a linear gradient against the same buffer without ammonium sulfate. Fractions containing the target enzyme were pooled and diafiltered with a $50 \mathrm{mM}$ sodium acetate buffer ( $\mathrm{pH}$ 5.5) using a hollow fibre crossflow module (Microza UF module SLP-1053, $10 \mathrm{kDa}$ cut-off, Pall Corporation). Concentrated $\mathrm{CDH}$ pools were applied to a column packed with Source 15Q material equilibrated with $50 \mathrm{mM}$ sodium acetate buffer ( $\mathrm{pH}$ 5.5) and eluted within a linear salt gradient from 0 to $1 \mathrm{M} \mathrm{NaCl}$ within 10 column volumes.

$\mathrm{NcLPMO}_{9 \mathrm{~F}}$ was purified by a three-step chromatographic procedure starting with hydrophobic interaction chromatography using PHE-Sepharose FF. The protein was loaded in $25 \mathrm{mM}$ sodium acetate buffer ( $\mathrm{pH} \mathrm{5.0)}$ ) containing 30\% ammonium sulfate (saturation), and eluted by a linear gradient. Fractions containing the enzyme were pooled and diafiltered with a $20 \mathrm{mM}$ Tris- $\mathrm{HCl}$ buffer ( $\mathrm{pH}$ 8.0) using a hollow fibre cross-flow module. After reaching a conductivity below $1.4 \mathrm{mS} \mathrm{cm}^{-1}$ the pool was applied to a column packed with Source $15 \mathrm{Q}$. The flow-through contained $N c \mathrm{LPMO}_{9 \mathrm{~F}}$ and was concentrated and further purified with size-exclusion chromatography using a Superdex 75 column equilibrated with $20 \mathrm{mM}$ Tris- $\mathrm{HCl}$ buffer ( $\mathrm{pH} 8.0$ ). Fractions containing pure $\mathrm{NcLPMO}_{9 \mathrm{~F}}$ were pooled, concentrated to a final concentration of $6.5 \mathrm{mg} \mathrm{ml}^{-1}$ and stored at $4{ }^{\circ} \mathrm{C}$.

Deglycosylation and proteolytic cleavage of CDHs. The purified CDHs were treated at $30^{\circ} \mathrm{C}$ for $18 \mathrm{~h}$ with $3,200 \mathrm{U} \mathrm{ml}^{-1} \alpha-1,2 / 3$-mannosidase and $50,000 \mathrm{U} \mathrm{ml}^{-1}$ endoglycosidase $\mathrm{H}_{\mathrm{f}}$ (New England Biolabs, Ipswich, MA, USA) in $50 \mathrm{mM}$ sodium acetate buffer (pH 5.5) containing $5 \mathrm{mM} \mathrm{ZnCl}_{2}$ to obtain $10 \mathrm{mg} \mathrm{ml}^{-1}$ deglycosylated enzyme. To remove the glycosidases, column chromatography with Source 15Q was repeated as described above and the fractions containing pure $\mathrm{CDH}$ were pooled, diafiltered to $50 \mathrm{mM}$ sodium acetate buffer $(\mathrm{pH} 5.5)$ and stored at $4{ }^{\circ} \mathrm{C}$. Proteolytic cleavage in the linker of $\mathrm{CDH}$ was performed to obtain the individual $\mathrm{DH}$ and CYT domains. To this end, $40 \mu \mathrm{l}$ of papain $\left(10 \mathrm{mg} \mathrm{ml}^{-1}\right)$ was incubated at $25^{\circ} \mathrm{C}$ for $1 \mathrm{~h}$ with $100 \mu \mathrm{l}$ of activation buffer containing $2 \mathrm{mM}$ EDTA and $2 \mathrm{mM}$ dithiothreitol in $100 \mathrm{mM}$ sodium phosphate ( $\mathrm{pH}$ 7.0). $\mathrm{CDH}$ (final concentration $10 \mathrm{mg} \mathrm{ml}^{-1}$ ) was digested in a reaction mix containing $140 \mu \mathrm{l}$ per $\mathrm{ml}$ of the activated papain solution and $1 \mathrm{M}$ sodium acetate $(\mathrm{pH} 5.0)$ at $25^{\circ} \mathrm{C}$ for $4 \mathrm{~h}$. The domains were separated from the residual intact $\mathrm{CDH}$ by column chromatography using a strong anion exchanger (Mono Q). The sample was diafiltered to $20 \mathrm{mM}$ Tris- $\mathrm{HCl}$ ( $\mathrm{pH} 8.0$ ), loaded on the column and eluted by a linear $\mathrm{NaCl}$ gradient. Fractions containing the dehydrogenase and the cytochrome domain were pooled, concentrated and stored at $4{ }^{\circ} \mathrm{C}$ for further use.

Kinetic characterization of MtCDH wild type and variants. Pre-steady-state measurements were carried out in a stopped-flow spectrophotometer (Applied Photophysics SX 20, Leatherhead, UK) at $30^{\circ} \mathrm{C}$. The concentration of enzymes was determined by their molar absorption coefficients $\left(\mathrm{NcCDH} \varepsilon_{420}=100 \mathrm{mM}^{-1} \mathrm{~cm}^{-1}\right.$, $\left.\mathrm{NcDH} \varepsilon_{450}=11.3 \mathrm{mM}^{-1} \mathrm{~cm}^{-1}, N_{c L P M O} \varepsilon_{280}=46.9 \mathrm{mM}^{-1} \mathrm{~cm}^{-1}\right)$. The FAD and haem $b$ reduction rates in $\mathrm{CDH}$ were measured at 449 and $563 \mathrm{~nm}$, respectively, by reducing $5 \mu \mathrm{M} \mathrm{CDH}$ with $25 \mathrm{mM}$ cellobiose (final concentrations) in $50 \mathrm{mM}$ sodium citrate buffer $\mathrm{pH}$ 5.0.

Electron transfer NcCYT-NcLPMO $_{95}$ and $\mathbf{N c D H - N c L P M O} \mathbf{9 F}_{\mathbf{9 F}}$. The same technique was used for measuring the ET between $\mathrm{NcCYT}$ or $\mathrm{NcDH}$ and $N_{c L P M O}$. NcCYT was partially reduced with sodium dithionite $(15 \mathrm{mM}$ stock solution) by following the spectra in a diode array photometer. By partial reduction, excess of reductant was prevented. The $50 \%$ reduced NcCYT was immediately transferred to a stopped-flow spectrophotometer and mixed with $N c \mathrm{LPMO}_{9 \mathrm{~F}}$ in single mode. Re-oxidation of the $\alpha$-band of $N c \mathrm{CYT}$ haem $b$ was recorded at $563 \mathrm{~nm}$. Concentrations in the cell were $4 \mu \mathrm{M}$ reduced $N c C Y T$ and $20 \mu \mathrm{M} \mathrm{NcLPMO}{ }_{9 \mathrm{~F}}$ in $50 \mathrm{mM}$ sodium citrate buffer $\mathrm{pH}$ 5.0. The observed rates were fitted to a single exponential function. Reduction and re-oxidation of the FAD cofactor in DH was followed at $450 \mathrm{~nm}$. Experiments were performed in sequential mode by mixing $40 \mu \mathrm{M} \mathrm{NcDH}$ with $100 \mu \mathrm{M}$ cellobiose to reduce the enzyme. The reaction was held in an ageing loop for $75 \mathrm{~s}$ until $\sim 10 \%$ of the $\mathrm{NcDH}$ was re-oxidized. The partly re-oxidized $\mathrm{NcDH}$ was shot against buffer or $N c \mathrm{LPMO}_{9 \mathrm{~F}}$ Final concentrations in the measuring cell were $10 \mu \mathrm{M} \mathrm{NcDH}$ and $50 \mu \mathrm{M}$ $\mathrm{NcLPMO}_{9 \mathrm{~F}}$. The rates were calculated from an exponential fit.
Crystallization, structure determination and model refinement. Data collection and refinement statistics are given in Table 2. All protein crystallization was performed using the sitting-drop vapour diffusion method at room temperature. Image processing and data scaling were performed with the XDS package ${ }^{41}$. When applicable, molecular replacement (MR) was performed using $P H A S E R^{42}$ as implemented in the PHENIX suite ${ }^{43}$, and unless otherwise stated experimental phasing was performed with autoSHARP ${ }^{44}$. Manual model building and correction was performed with the programs $O^{45}$ and $\mathrm{COOT}^{46}$. Experimental details for each protein are given below. For models refined at lower resolution, the resolution cutoff for refinement was guided by the $C C(1 / 2)$ values, that is, the percentage of correlation between intensities from random half data sets ${ }^{47}$

MtCYT (MtCDH cytochrome domain). Crystals of deglycosylated MtCYT were obtained by mixing equal volumes of protein solution $\left(21 \mathrm{mg} \mathrm{ml}^{-1}\right.$ in $20 \mathrm{mM}$ HEPES pH 7.5) and a solution containing $0.1 \mathrm{M}$ Tris- $\mathrm{HCl}(\mathrm{pH} 8.4), 0.2 \mathrm{M} \mathrm{MgCl}_{2}$, $30 \%(\mathrm{w} / \mathrm{v})$ polyethylene glycol 4,000. The crystals belong to space group $P 2_{1}$ with two molecules in the asymmetric unit. A model for molecular replacement (MR) was generated automatically using the $B A L B E S$ server ${ }^{48}$. MR calculations were performed with $P H A S E R$, and a model was traced and built automatically using data to $1.4 \AA$ resolution with the warpNtrace function in $A R P / w A R P^{49}$. The model was refined at $1.4 \AA$ resolution with PHENIX, using the maximum-likelihood target and including refinement of coordinates, real-space refinement and refinement of individual anisotropic temperature factors (Table 2; Supplementary Fig. 10a). The refined model contains: two protein chains, A and B, each composed of residues 1-208 (corresponding to residues 22-229 in UniProt A9XK88); one type- $b$ protoheme IX group per protein chain; protein glycosylation (one $\mathrm{N}$-acetyl glucosamine, NAG, residue attached to Asn119, and four O-linked mannose residues attached to Ser195, Thr197, Thr204 and Thr206, respectively, per protein chain); one magnesium ion bound to protein chain A and two magnesium ions to chain $\mathrm{B}$; and 350 water molecules.

$\mathrm{MtDH}$ (MtCDH dehydrogenase domain). Non-deglycosylated $\mathrm{MtDH}$ crystallized from mixing equal volumes of a solution containing $0.1 \mathrm{M}$ sodium acetate ( $\mathrm{pH} 4.6), 0.1 \mathrm{M} \mathrm{CdCl}_{2}, 18 \%(\mathrm{w} / \mathrm{v})$ polyethylene glycol monomethyl ether 550 with protein $\left(58 \mathrm{mg} \mathrm{ml}^{-1}\right.$ in $20 \mathrm{mM}$ HEPES $\mathrm{pH} 7.5$ ). The crystals belong to space group $P 6_{3}$ with one molecule in the asymmetric unit. Cryo protection was performed by equilibration in a solution containing the crystallization liquor, but with $30 \%(w / v)$ polyethylene glycol monomethyl ether 550 . Data were collected on a native crystal, as well as two heavy-atom derivatives, lead acetate and mercury acetate. The heavy atoms were added as powder to the cryo-protection solution and the crystals left to equilibrate in the presence of heavy atom for $1 \mathrm{~min}$ before being vitrified in liquid nitrogen. For the complex of $M t \mathrm{DH}$ with the inhibitor 5-amino-5-deoxy-cellobiono-1,5-lactam (CBLM) a crystal was used that resulted from equal volumes of $58 \mathrm{mg} \mathrm{ml}^{-1}$ protein in $20 \mathrm{mM}$ HEPES pH 7.5 and $0.1 \mathrm{M}$ sodium acetate ( $\mathrm{pH} 4.6), 0.1 \mathrm{M} \mathrm{CdCl}_{2}, 15 \%$ (w/v) polyethylene glycol monomethy ether 2000 . The crystal was equilibrated in a solution containing $0.1 \mathrm{M}$ sodium acetate ( $\mathrm{pH} 4.6), 0.1 \mathrm{M} \mathrm{CdCl}_{2}, 30 \%(\mathrm{w} / \mathrm{v})$ polyethylene glycol monomethyl ether 2000 and $2 \mathrm{mM}$ cellobionolactam inhibitor.

The $M t \mathrm{DH}$ structure was determined using multiple isomorphous replacement with anomalous scattering (MIRAS) with lead acetate and mercury acetate using autoSHARP ${ }^{44}$. SHELXD ${ }^{50}$ in autoSHARP was used to locate the heavy-atom positions, and $S H A R P^{44}$ to refine heavy-atom positions and calculate phases. Density modification using a solvent content of $66 \%$ was performed with SOLOMON in autoSHARP and DM in the CCP4 suite ${ }^{51}$. The final MIRAS phases to $3 \AA$ were of high quality and during the process of iterative model building and refinement, averaged structure factors from the derivatives where the heavy-atom contribution had been removed $\left(F_{\mathrm{av}}\right)$ were used together with HendricksonLattman coefficients to allow phase combination of experimental MIRAS phases with partial model phases $\left(F_{\mathrm{c}}\right)$ in $R E F M A C 5^{52}$ to improve refinement, phases and $2 F_{0}-F_{\mathrm{c}}$ electron density quality. The structure of the $M t \mathrm{DH}-\mathrm{CBLM}$ complex was determined by MR with PHASER using the $M t \mathrm{DH}$ model as search probe.

The software PHENIX was used to refine the $M t \mathrm{DH}$ and $M t \mathrm{DH}-\mathrm{CBLM}$ models at 2.7 and $2.4 \AA$ resolution, respectively (Table 2; Supplementary Fig. 10b,c). Refinement incorporated the maximum-likelihood target, refinement of coordinates, real-space refinement, refinement of individual isotropic temperature factors and translation-libration-screw (TLS) refinement using TLS groups derived by the PHENIX software (five groups for $M t \mathrm{DH}$ and six groups for $M t \mathrm{DH}-\mathrm{CBLM}$ ). The refined $M t \mathrm{DH}$ model contains: one protein chain (A) composed of residues 223-807 (corresponding to residues 244-828 in UniProt A9XK88); one noncovalently bound FAD molecule; protein glycosylation (two NAG residues attached to Asn400, two NAG residues at Asn437, and one NAG at Asn516); 9 cadmium ions; and no water molecules. The resulting $M t \mathrm{DH}-\mathrm{CBLM}$ model contains: one protein chain (A) composed of residues 223-807; one non-covalently bound FAD molecule; protein glycosylation (two NAG residues attached to Asn400 and two NAG residues at Asn437); one CBLM molecule; two cadmium ions; and 182 water molecules.

$\mathrm{MtCDH}$. Deglycosylated $\mathrm{MtCDH}$ was crystallized from mixing equal volumes of $0.1 \mathrm{M}$ MES-OH (pH 6.5), $0.1 \mathrm{M}$ ammonium sulfate, $0.4 \mathrm{M}$ sodium formate, $30 \%(\mathrm{w} / \mathrm{v})$ polyethylene glycol monomethyl ether 5,000 with protein $\left(84 \mathrm{mg} \mathrm{ml}^{-1}\right.$ in $20 \mathrm{mM}$ sodium acetate $\mathrm{pH} 5.5$ ). The crystals were in point group 422 , with one molecule in the asymmetric unit. The space group was deduced at the structure determination stage. The individual $M t C Y T$ and $M t \mathrm{DH}$ domains, refined at $1.4 \AA$ and $3.0 \AA$ resolution, respectively, and $M t C D H$ data $(4.5-15 \AA)$ were used for MR 
Table 2 | Data collection, phasing and refinement statistics.

\begin{tabular}{|c|c|c|c|c|c|c|c|c|c|}
\hline & MtCYT & MtDH & $\begin{array}{c}\text { MtDH } \\
\text { Hg-MIR }\end{array}$ & $\begin{array}{c}\text { MtDH } \\
\text { Pb-MIR }\end{array}$ & $\begin{array}{l}\text { MtDH } \\
\text { CBLM }\end{array}$ & MtCDH & $\begin{array}{l}\text { NcCDH } \\
\text { Pt-SAD }\end{array}$ & NcLPMO $_{9 F}$ & $\begin{array}{c}\text { NcLPMO }_{9 F} \\
\text { Cu-SAD }\end{array}$ \\
\hline \multicolumn{10}{|l|}{ Data collection } \\
\hline Space group & $P 2_{1}$ & $\mathrm{PG}_{3}$ & $P 6_{3}$ & $P 6_{3}$ & $\mathrm{PG}_{3}$ & $P 4_{3} 2_{1} 2$ & $P 2_{1} 2_{1} 2_{1}$ & $P 2{ }_{1} 2_{1} 2$ & $P 2{ }_{1} 2_{1} 2$ \\
\hline $\begin{array}{l}\text { Cell dimensions } \\
a, b, c(\AA)\end{array}$ & $\begin{array}{c}49.4,56.4 \\
73.0\end{array}$ & $\begin{array}{c}171.8,171.8 \\
72.0\end{array}$ & $\begin{array}{c}171.6,171.6 \\
73.0\end{array}$ & $\begin{array}{c}171.8,171.8 \\
72.4\end{array}$ & $\begin{array}{c}171.3,171.3 \\
73.0\end{array}$ & $\begin{array}{c}156.2,156.2 \\
85.3\end{array}$ & $\begin{array}{c}133.6,141.8 \\
147.0\end{array}$ & $\begin{array}{c}71.7,162.5 \\
33.0\end{array}$ & $\begin{array}{c}71.8,163.0 \\
33.1\end{array}$ \\
\hline$\alpha, \beta, \gamma\left(^{\circ}\right)$ & $\begin{array}{c}90,104.6 \\
90\end{array}$ & $90,90,120$ & $90,90,120$ & $90,90,120$ & $90,90,120$ & $90,90,120$ & $90,90,90$ & $90,90,90$ & $90,90,90$ \\
\hline Resolution $(\AA)^{\star}$ & $\begin{array}{c}48-1.40 \\
(1.50-1.40)\end{array}$ & $\begin{array}{c}44-2.70 \\
(2.80-2.70)\end{array}$ & $\begin{array}{c}45-2.60 \\
(2.70-2.60)\end{array}$ & $\begin{array}{c}44-2.70 \\
(2.80-2.70)\end{array}$ & $\begin{array}{c}44-2.40 \\
(2.50-2.40)\end{array}$ & $\begin{array}{c}46-3.20 \\
(3.30-3.20)\end{array}$ & $\begin{array}{c}59-2.90 \\
(3.00-2.90)\end{array}$ & $\begin{array}{c}43-1.10 \\
(1.20-1.10)\end{array}$ & $\begin{array}{c}43-1.70 \\
(1.80-1.70)\end{array}$ \\
\hline$R_{\mathrm{sym}}$ & $\begin{array}{c}0.041 \\
(0.815)\end{array}$ & $\begin{array}{c}0.092 \\
(1.743)\end{array}$ & $\begin{array}{c}0.115 \\
(1.789)\end{array}$ & $\begin{array}{c}0.184 \\
(2.210)\end{array}$ & $\begin{array}{c}0.254 \\
(3.589)\end{array}$ & $\begin{array}{c}0.288 \\
(2.696)\end{array}$ & $\begin{array}{c}0.289 \\
(3.680)\end{array}$ & $\begin{array}{c}0.058 \\
(0.221)\end{array}$ & $\begin{array}{c}0.060 \\
(0.078)\end{array}$ \\
\hline$|/ \sigma|$ & $18.1(1.8)$ & $16.3(1.1)$ & $12.3(1.1)$ & $12.3(1.1)$ & $12.3(1.1)$ & $7.7(1.2)$ & $13.6(1.2)$ & $23.9(9.1)$ & $24.0(12.1)$ \\
\hline Completeness (\%) & $99.1(99.2)$ & 99.9 (99.9) & 99.9 (99.8) & 99.9 (99.9) & 99.7 (99.3) & 99.9 (99.8) & 99.9 (99.9) & $96.2(83.7)$ & $91.7(60.5)$ \\
\hline Redundancy & $3.7(3.6)$ & $7.2(5.6)$ & $6.5(6.4)$ & $8.6(8.4)$ & $19.6(17.8)$ & $12.0(11.5)$ & $14.6(15.0)$ & $11.9(9.2)$ & $6.3(2.9)$ \\
\hline $\operatorname{CC}(1 / 2)^{\dagger}$ & $\begin{array}{l}100.0 \\
(68.7)\end{array}$ & $99.9(38.0)$ & $99.9(45.3)$ & $99.7(44.6)$ & $99.7(58.4)$ & $99.4(36.3)$ & $99.8(48.4)$ & $99.9(97.6)$ & $99.7(98.6)$ \\
\hline $\begin{array}{l}\text { Resolution limit }(\AA) \text { at } \\
I / \sigma I=2\end{array}$ & 1.43 & 2.81 & 2.74 & 2.91 & 2.62 & 3.40 & 3.01 & - & - \\
\hline Wilson B-factor $\left(\AA^{2}\right)$ & 15.2 & 75.4 & 66.4 & 63.2 & 40.9 & 91.7 & 71.1 & 8.0 & 22.5 \\
\hline \multicolumn{10}{|l|}{ Refinement } \\
\hline Resolution $(\AA)$ & 1.40 & 2.70 & - & - & 2.40 & 3.20 & 2.90 & 1.10 & - \\
\hline No. reflections (all) & 77,847 & 35,510 & - & - & 49,376 & 17,929 & 62,454 & 153,530 & - \\
\hline $\begin{array}{l}R_{\text {work }} / R_{\text {free }} \\
\text { Number of atoms }\end{array}$ & $0.18 / 0.23$ & $0.18 / 0.23$ & - & - & $0.20 / 0.24$ & $0.24 / 0.29$ & $0.19 / 0.24$ & $0.13 / 0.15$ & - \\
\hline Protein (all) & 3,696 & 4,588 & - & - & 4,776 & 6,262 & 12,482 & 4,264 & - \\
\hline Ligand/ion & 205 & 132 & - & - & 134 & 207 & 442 & 6 & - \\
\hline Water & 350 & 0 & - & - & 182 & 0 & 0 & 838 & - \\
\hline \multicolumn{10}{|l|}{ B-factors } \\
\hline Protein (all) & 25.6 & 82.6 & - & - & 42.7 & 78.2 & 80.6 & 10.3 & - \\
\hline Ligand/ion & 39.3 & 97.5 & - & - & 56.3 & 68.2 & 86.9 & 10.6 & - \\
\hline Water & 37.0 & - & - & - & 43.7 & - & - & 22.7 & - \\
\hline \multicolumn{10}{|l|}{ R.m.s deviations } \\
\hline Bond lengths $(\AA)$ & 0.009 & 0.010 & - & - & 0.009 & 0.005 & 0.012 & 0.007 & - \\
\hline Bond angles $\left({ }^{\circ}\right)$ & 2.48 & 1.39 & - & - & 1.37 & 1.25 & 1.78 & 1.25 & - \\
\hline $\begin{array}{l}\text { Ramachandran } \\
\text { favored }(\%)^{\ddagger}\end{array}$ & 97.1 & 97.6 & - & - & 97.4 & 95.5 & 95.2 & 96.4 & - \\
\hline $\begin{array}{l}\text { Ramachandran } \\
\text { outliers (\%) }\end{array}$ & 0 & 0 & - & - & 0 & 1 & 3 & 0 & - \\
\hline PDB accession code & 4QI3 & 4Q|4 & & & 4QI5 & 4Q16 & 4Q।7 & 4Q18 & \\
\hline $\begin{array}{l}\text { Only one crystal was used for } \\
{ }^{*} \text { Highest resolution shell is shov } \\
\dagger \text { Percentage of correlation betw } \\
\ddagger \text { As determined by MolProbity }\end{array}$ & $\begin{array}{l}\text { refined stru } \\
\text { parenthesis } \\
\text { intensities } \mathrm{fr}\end{array}$ & 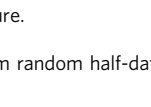 & & & Vt & 列 & 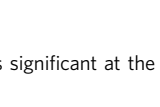 & $\%$ level. & \\
\hline
\end{tabular}

calculations using PHASER. All possible PG422 enantiomorphs were tested, returning a clear solution only in space group $P 4_{3} 2_{1} 2$. The $M t \mathrm{CDH}$ model was refined against the maximum-likelihood target in PHENIX at $3.2 \AA$ resolution (Table 2; Supplementary Fig. 11a) using a refinement protocol including XYZ coordinate refinement, refinement of grouped isotropic temperature factors (two groups per residue). The refined $M t \mathrm{CDH}$ model contains one protein chain (A) composed of residues 1-807 (corresponding to residues 22-828 in UniProt A9XK88; 1-21 belong to the signal peptide) with residues $211-217$ of the linker missing; one type- $b$ protoheme IX group; one non-covalently bound FAD molecule; and protein glycosylation (one NAG residue attached to Asn400, Asn437, Asn516 and Asn678; one mannose residue attached to Ser195, Thr197, Thr204, Thr206 and Thr226).

$\mathrm{NcCDH}$. Deglycosylated $\mathrm{NcCDH}$ was crystallized from mixing equal volumes of $0.1 \mathrm{M}$ MES-OH ( $\mathrm{pH} 6.5), 1.5 \mathrm{M}$ magnesium sulfate, $0.02 \mathrm{M}$ lithium sulfate with protein $\left(36 \mathrm{mg} \mathrm{m}^{-1}\right.$ in $20 \mathrm{mM}$ sodium acetate $\mathrm{pH}$ 5.5). Crystals were equilibrated in the crystallization solution supplemented with $50 \%$ saturated lithium sulfate before being vitrified in liquid nitrogen. The crystals were in space group $P 2_{1} 2_{1} 2_{1}$ with two molecules in the asymmetric unit. The platinum derivative was produced by adding $\mathrm{K}_{2} \mathrm{Pt}(\mathrm{CN}) 4$ powder to a drop containing the crystal in its mother liquor. Initial phasing was performed using Pt-SAD in autoSHARP. Phases were improved by density modification with SOLOMON using a solvent content of $61.3 \%$ to $2.9 \AA$ resolution. To facilitate model building, the $M t C Y T$ and $M t D H$ domains were placed in the $\mathrm{NcCDH}$ unit cell using MR calculations with PHASER. Model re-building was guided by MR- and SAD-phased electron-density maps. Both $\mathrm{NcCDH}$ molecules in the asymmetric unit are in the open conformation with dissociated CYT and DH domains. The inherent flexibility of the linker connecting the CYT and DH domains resulted in different NCS symmetry for the CYT and $\mathrm{DH}$ domain pairs in the asymmetric unit, and partly disordered linker regions.
The $\mathrm{NcCDH}$ model was refined using the maximum-likelihood target in PHENIX at $2.9 \AA$ resolution (Table 2; Supplementary Fig. 11b) using a refinement protocol including $X Y Z$ coordinate refinement, refinement of individual isotropic temperature factors and TLS refinement (six groups). The refined model contains two protein chains (A and B) composed of residues 2-806 (corresponding to residues 25-829 in UniProt Q7RXM0; 1-23 belongs to the signal peptide) with residues 206-217 in the linker missing in protein chain B; one type-b protoheme IX group and one non-covalently bound FAD molecule per protein chain; protein glycosylation (Asn119, Asn278, Asn400, Asn471, Asn515, Asn541 and Asn555 each have one $N$-linked NAG residue); one mannose residue attached to Thr222 and Thr226; and 10 platinum atoms bound per protein chain.

$N C L P M O_{9 F} . N C L P M O_{9 F}$ is natively non-glycosylated and contains one copper centre. The copper content of purified $\mathrm{NcLPMO}_{9 \mathrm{~F}}$ was analysed by inductively coupled plasma atomic emission spectroscopy, ICP-AES, and sector field inductively coupled plasma mass spectroscopy, ICP-SMS (ALS Scandinavia AB). Crystals of $N c L P M O{ }_{9 F}$ were produced by mixing $0.1 \mu \mathrm{l}$ of protein $\left(30 \mathrm{mg} \mathrm{ml}^{-1}\right.$ in $50 \mathrm{mM}$ Tris $\mathrm{pH} 8.0$ ) with $0.2 \mu \mathrm{l}$ of reservoir solution containing $0.2 \mathrm{M}$ ammonium nitrate and $20 \%(\mathrm{w} / \mathrm{v})$ polyethylene glycol 3350 . The crystals belong to space group $P 2_{1} 2_{1} 2$ with two molecules in the asymmetric unit. Structure determination was performed by taking advantage of the copper centre for Cu-SAD using the AutoSol and AutoBuild modules in PHENIX. The best SAD solution had an estimated map CC $\times 100$ of $29.0+/-28.3$. Density modification and model building were performed iteratively by RESOLVE ${ }^{53}$ using a default solvent content of $50 \%$, yielding a model with an $R$ factor of 0.28 and a correlation of local RMS density of

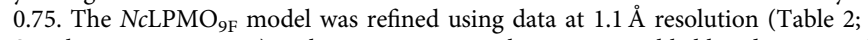
Supplementary Fig. 11c) with PHENIX, using the maximum-likelihood target and including refinement of $X Y Z$ coordinates, real-space refinement, refinement of individual anisotropic temperature factors, and riding hydrogen atoms. The refined 
$N_{c L P M O}{ }_{9 \mathrm{E}}$ model contains two protein chains (A and B) each composed of residues 1-214 (corresponding to residues 18-231 in UniProt Q1K4Q1; 1-17 constitutes a signal peptide); one copper per protein chain; one nitrate molecule in chain $\mathrm{B}$, and 838 water molecules. Modelling of $\mathrm{NcCDH}-\mathrm{NcLPMO}_{9 \mathrm{~F}}$ was performed by manual docking of $\mathrm{NcCDH} C Y \mathrm{~T}$ such that the haem $b$ propionate-A carboxyl group superimposed with that of the copper-coordinating Asp33 in NCS molecule A of $N_{c} \mathrm{LPMO}_{9 \mathrm{~F}}$.

SAXS data collection and analysis. Samples of deglycosylated and glycosylated $M t C D H$ and $N c C D H$ were prepared at the concentrations $1,2.5$ and $10 \mathrm{mg} \mathrm{ml}^{-1}$ in $50 \mathrm{mM}$ sodium acetate (pH 4.5), and in the absence or presence of $1 \mathrm{mM}$ CBLM. Data were collected through mail-in-SAXS on the 12.3.1 SIBYLS beamline at the Advanced Light Source, Lawrence Berkeley National Laboratory ${ }^{54,55}$, and at the MAX II SAXS beamline 1911-SAXS ${ }^{56}$ at MAX IV Laboratory, Lund, Sweden. Data were processed using PRIMUS ${ }^{57}$ in the ATSAS suite ${ }^{31}$. The ensemble optimization modelling method $\mathrm{d}^{30,31}$ was used to generate the most populated clusters of conformers in an ensemble that best fits the scattering data. The crystal structures of CYT and DH were input as domains and 10,000 models with different domain orientations and automatically modelled linkers were generated within the EOM 2.0 framework $^{58}$.

Chemical cross-linking. Deglycosylated and glycosylated $\mathrm{MtCDH}$ and $\mathrm{NcCDH}$ were diluted to a final concentration of $0.5-1 \mathrm{mg} \mathrm{ml}^{-1}$ with $50 \mathrm{mM}$ HEPES buffer ( $\mathrm{pH}$ 7.5). The cross-linking was performed by adding glutaraldehyde at a final concentration of $0.5 \%(\mathrm{v} / \mathrm{v})$ to the diluted protein solutions. The effect of cross-linking was tested in the absence and in the presence of $1 \mathrm{mM}$ EDTA. Samples were taken before adding the cross-linker as well as at $t=5,15,30$ and $60 \mathrm{~min}$ after adding the cross-linker. One molar Tris buffer $\mathrm{pH} 7.5$ was immediately added to the samples to neutralize the cross-linker and stop the reaction, after which the samples were mixed with sample buffer and reducing agents ( $50 \mathrm{mM}$ dithiothreitol), heated for $5 \mathrm{~min}$ at $75^{\circ} \mathrm{C}$, and loaded on $3-8 \%$ NuPAGE Tris Acetate gels (Life technologies)

Automated molecular docking of $\mathbf{N C C D H - C Y T}$ and $\mathbf{N C L P M O}_{\mathbf{9 F}}$. We performed automated molecular docking of $\mathrm{NcLPMO}_{9 \mathrm{~F}}$ and $\mathrm{NcCDH}$ with the program HADDOCK 2.0 (http://haddock.science.uu.nl/services/HADDOCK/ haddock.ph $\left.{ }^{59-61}\right)$. The program requires suggestions for interacting regions, and two hypotheses were tested. One protocol evaluated an interaction between the previously proposed surface patch on $\mathrm{LPMO}^{23}$ and the haem in CYT, and another protocol tested an interaction between the copper-binding surface of LPMO and haem. Only the structures of the $N c C Y T$ domain and $N c L P M O_{9 F}$ were used.

Illustrations. Figures were produced using the program PyMOL (DeLano, www.pymol.org).

\section{References}

1. Himmel, M. E. et al. Biomass recalcitrance: engineering plants and enzymes for biofuel production. Science 315, 804-807 (2007).

2. Gelfand, I. et al. Sustainable bioenergy production from marginal lands in the US Midwest. Nature 493, 514-517 (2013).

3. Eriksson, K.-E., Pettersson, B. \& Westermark, U. Oxidation: an important enzyme reaction in fungal degradation of cellulose. FEBS Lett. 49, 282-285 (1974).

4. Bao, W. J. \& Renganathan, R. Cellobiose oxidase of Phanerochaete chrysosporium enhances crystalline cellulose degradation by cellulases. FEBS Lett. 302, 77-80 (1992).

5. Henriksson, G., Ander, P., Pettersson, B. \& Pettersson, G. Cellobiose dehydrogenase (cellobiose oxidase) from Phanerochaete chrysosporium as a wood degrading enzyme. Studies on cellulose, xylan and synthetic lignin. Appl. Microbiol. Biotechnol. 42, 790-796 (1995).

6. Dumonceaux, T., Bartholomew, K., Valeanu, L., Charles, T. \& Archibald, F. Cellobiose dehydrogenase is essential for wood invasion and nonessential for kraft pulp delignification by Trametes versicolor. Enzyme Microb. Technol. 29, 478-489 (2001).

7. Canam, T., Town, J. R., Tsang, A., McAllister, T. A. \& Dumonceaux, T. J. Biological pretreatment with a cellobiose dehydrogenase-deficient strain of Trametes versicolor enhances the biofuel potential of canola straw. Bioresource Technol. 102, 10020-10027 (2011).

8. Harris, P. V. et al. Stimulation of lignocellulosic biomass hydrolysis by proteins of glycoside family 61: structure and function of a large enigmatic family. Biochemistry 49, 3305-3316 (2010).

9. Vaaje-Kolstad, G. et al. An oxidative enzyme boosting the enzymatic conversion of recalcitrant polysaccharides. Science 330, 219-222 (2010).

10. Quinlan, R. J. et al. Insights into the oxidative degradation of cellulose by a copper metalloenzyme that exploits biomass components. Proc. Natl Acad. Sci. USA 108, 15079-15084 (2011).
11. Horn, S. J., Vaaje-Kolstad, G., Westereng, B. \& Eijsink, V. G. Novel enzymes for the degradation of cellulose. Biotechnol. Biofuels 5, 45 (2011).

12. Agger, J. W. et al. Discovery of LPMO activity on hemicelluloses shows the importance of oxidative processes in plant cell wall degradation. Proc. Natl Acad. Sci. USA 111, 6287-6292 (2014).

13. Vu, V. V., Beeson, W. T., Span, E. A., Farquhar, E. R. \& Marletta, M. A. A family of starch-active polysaccharide monooxygenases. Proc. Natl Acad. Sci. USA 111, 13822-13827 (2014).

14. Tian, C. et al. Systems analysis of plant cell wall degradation by the model filamentous fungus Neurospora crassa. Proc. Natl Acad. Sci. USA 106, 22157-22162 (2009).

15. Phillips, C. M., Beeson, IV W. T., Cate, J. H. \& Marletta, M. A. Cellobiose dehydrogenase and a copper-dependent polysaccharide monooxygenase potentiate cellulose degradation by Neurospora crassa. ACS Chem. Biol. 6, 1399-1406 (2011).

16. Langston, J. A. et al. Oxidoreductive cellulose depolymerization by the enzymes cellobiose dehydrogenase and glycoside hydrolase 61. Appl. Environ. Microbiol. 77, 7007-7015 (2011).

17. Beeson, W. T., Phillips, C. M., Cate, J. H. D. \& Marletta, M. A. Oxidative cleavage of cellulose by fungal copper-dependent polysaccharide monooxygenases. J. Am. Chem. Soc. 134, 890-892 (2011).

18. Turbe-Doan, A., Arfi, Y., Record, E., Estrada-Alvarado, I. \& Levasseur, A. Heterologous production of cellobiose dehydrogenases from the basidiomycete Coprinopsis cinerea and the ascomycete Podospora anserina and their effect on saccharification of wheat straw. Appl. Microbiol. Biotechnol. 97, 4873-4885 (2013).

19. Payne, C. M. et al. Fungal cellulases. Chem. Rev. 115, 1308-1448 (2015).

20. Zamocky, M. et al. Cellobiose dehydrogenase-a flavocytochrome from wood-degrading, phytopathogenic and saprotropic fungi. Curr. Protein Pept. Sci. 7, 255-280 (2006).

21. Harreither, W. et al. Catalytic properties and classification of cellobiose dehydrogenases from ascomycetes. Appl. Environ. Microbiol. 77, 1804-1815 (2011).

22. Henriksson, G., Salumets, A., Divne, C. \& Pettersson, G. Studies of cellulose binding by cellobiose dehydrogenase and a comparison with cellobiohydrolase 1. Biochem. J. 324, 833-838 (1997).

23. Li, X. et al. Structural basis for substrate targeting and catalysis by fungal polysaccharide monooxygenases. Structure 20, 1051-1061 (2012).

24. Kim, S., Ståhlberg, J., Sandgren, M., Paton, R. S. \& Beckham, G. T. Quantum mechanical calculations suggest that lytic polysaccharide monooxygenases use a copper-oxyl, oxygen-rebound mechanism. Proc. Natl Acad. Sci. USA 111, 149-154 (2014).

25. Hallberg, B. M. et al. A new scaffold for binding haem in the cytochrome domain of the extracellular flavocytochrome cellobiose dehydrogenase. Structure 8, 79-88 (2000).

26. Hallberg, B. M., Henriksson, G., Pettersson, G. \& Divne, C. Crystal structure of the flavoprotein domain of the extracellular flavocytochrome cellobiose dehydrogenase. J. Mol. Biol. 315, 421-434 (2002).

27. Page, C. C., Moser, C. C., Chen, X. \& Dutton, P. L. Natural engineering principles of electron tunnelling in biological oxidation-reduction. Nature 402, 47-52 (1999).

28. Lederer, F. Another look at the interaction between mitochondrial cytochrome $c$ and flavocytochrome b2. Eur. Biophys. J. 40, 1283-1299 (2011).

29. Hallberg, B. M., Henriksson, G., Pettersson, G., Vasella, A. \& Divne, C. Mechanism of the reductive half-reaction in cellobiose dehydrogenase. J. Biol. Chem. 278, 7160-7166 (2003).

30. Bernado, P., Mylonas, E., Petoukhov, M. V., Blackledge, M. \& Svergun, D. I. Structural Characterization of flexible proteins using small-angle X-ray scattering. J. Am. Chem. Soc. 129, 5656-5664 (2007).

31. Petoukhov, M. V. et al. New developments in the ATSAS program package for small-angle scattering data analysis. J. Appl. Crystallogr. 45, 342-350 (2012).

32. Eibinger, M. et al. Cellulose surface degradation by a lytic polysaccharide monooxygenase and its effect on cellulose hydrolytic efficiency. J. Biol. Chem. 289, 35929-35938 (2014).

33. Wu, M. et al. Crystal structure and computational characterization of the lytic polysaccharide monooxygenase GH61D from the basidiomycota fungus Phanerochaete chrysosporium. J. Biol. Chem. 288, 12828-12839 (2013).

34. Forsberg, Z. et al. Structural and functional characterization of a conserved pair of bacterial cellulose-oxidizing lytic polysaccharide monooxygenases. Proc. Natl Acad. Sci. USA 111, 8446-8451 (2014).

35. Guallar, V. Haem electron transfer in peroxidases: the propionate e-pathway. J. Phys. Chem. B 112, 13460-13464 (2008).

36. Zamocky, M. et al. Cloning, sequence analysis and heterologous expression in Pichia pastoris of a gene encoding a thermostable cellobiose dehydrogenase from Myriococcum thermophilum. Protein Express. Purif. 59, 258-265 (2008).

37. Levasseur, A., Drula, E., Lombard, V., Coutinho, P. M. \& Henrissat, B. Expansion of the enzymatic repertoire of the CAZy database to integrate auxiliary redox enzymes. Biotechnol. Biofuels 6, 41 (2013). 
38. Kittl, R., Kracher, D., Burgstaller, D., Haltrich, D. \& Ludwig, R. Production of four Neurospora crassa lytic polysaccharide monooxygenases in Pichia pastoris monitored by a fluorimetric assay. Biotechnol. Biofuels 5, 79 (2012).

39. Sygmund, C. et al. Characterization of the two Neurospora crassa cellobiose dehydrogenases and their connection to oxidative cellulose degradation. Appl. Environ. Microbiol. 78, 6161-6171 (2012).

40. Flitsch, A. et al. Cellulose oxidation and bleaching processes based on recombinant Myriococcum thermophilum cellobiose dehydrogenase. Enzyme Microb. Technol. 52, 60-67 (2013).

41. Kabsch, W. Automatic processing of rotation diffraction data from crystals of initially unknown symmetry and cell constants. J. Appl. Crystallogr. 26, 795-800 (1993).

42. McCoy, A. J. et al. Phaser crystallographic software. J. Appl. Crystallogr. 40, 658-674 (2007)

43. Adams, P. D. et al. PHENIX: a comprehensive Python-based system for macromolecular structure solution. Acta Crystallogr. D 66, 213-221 (2010).

44. Vonrhein, C., Blanc, E., Roversi, P. \& Bricogne, G. Automated structure solution with autoSHARP. Methods Mol. Biol. 364, 215-230 (2007).

45. Jones, T. A., Zou, J. Y., Cowan, S. W. \& Kjeldgaard, M. Improved methods for building protein models in electron density maps and the location of errors in these models. Acta Crystallogr. A 47, 110-119 (1991).

46. Emsley, P. \& Cowtan, K. Coot: model-building tools for molecular graphics. Acta Crystallogr. D 60, 2126-2132 (2004).

47. Karplus, P. A. \& Diederichs, K. Linking crystallographic model and data quality. Science 336, 1030-1033 (2012).

48. Long, F., Vagin, A. A., Young, P. \& Murshudov, G. N. BALBES: a molecular replacement pipeline. Acta Crystallogr. D 64, 125-132 (2008).

49. Langer, G., Cohen, S. X., Lamzin, V. S. \& Perrakis, A. Automated macromolecular model building for X-ray crystallography using ARP/wARP version 7. Nat. Protoc. 3, 1171-1179 (2008).

50. Sheldrick, G. M. Experimental phasing with SHELXC/D/E: combining chain tracing with density modification. Acta Crystallogr. D 66, 479-485 (2010).

51. Collaborative Computational Project, Number 4. The CCP4 suite: programs for protein crystallography. Acta Crystallogr. D 50, 760-763 (1994).

52. Murshudov, G. N. et al. REFMAC5 for the refinement of macromolecular crystal structures. Acta Crystallogr. D 67, 355-367 (2011).

53. Terwilliger, T. C. Automated main-chain model building by template matching and iterative fragment extension. Acta Crystallogr. D 59, 38-44 (2003).

54. Hura, G. L. et al. Robust, high-throughput solution structural analyses by small angle X-ray scattering (SAXS). Nat. Method 6, 606-612 (2009).

55. Putnam, C. D., Hammel, M., Hura, G. L. \& Tainer, J. A. X-ray solution scattering (SAXS) combined with crystallography and computation: Defining accurate macromolecular structures, conformations and assemblies in solution. Q. Rev. Biophys. 40, 191-285 (2007)

56. Labrador, A., Cerenius, Y., Svensson, C., Keld, T. \& Plivelic, T. The yellow mini-hutch for SAXS experiments at MAX IV Laboratory. J. Phys.: Conf. Series 425, 072019 (2013).

57. Konarev, P. V., Volkov, V. V., Sokolova, A. V., Koch, M. H. J. \& Svergun, D. I. PRIMUS: A Windows PC-based system for small-angle scattering data analysis. J. Appl. Crystallogr. 36, 1277-1282 (2003).

58. Tria, G., Mertens, H. D. T., Kachala, M. \& Svergun, D. I. Advanced ensemble modelling of flexible macromolecules using X-ray solution scattering. IUCrJ 2, 207-217 (2015)

59. de Vries, S. J. et al. HADDOCK versus HADDOCK: New features and performance of HADDOCK2.0 on the CAPRI targets. Proteins: Struc. Funct. Bioinformatics 69, 726-733 (2007).

60. de Vries, S. J., van Dijk, M. \& Bonvin, A. M. J. J. The HADDOCK web server for data-driven biomolecular docking. Nat. Protoc. 5, 883-897 (2010)

61. Wassenaar et al. WeNMR: structural biology on the grid. J. Grid. Comp. 10, 743-767 (2012)

62. Vincent, B. et al. MolProbity: all-atom structure validation for macromolecular crystallography. Acta Crystallogr. D. 66, 12-21 (2010).

\section{Acknowledgements}

We thank the beamline staff scientists for support during data collection at beamlines $I 24$ and $I 02$ at Diamond Light Source and ID23-1 at ESRF Grenoble. A. Vasella is thanked for providing the CBLM inhibitor. We acknowledge financial support to C.D. from the Swedish Research Council FORMAS (grants $N^{\circ} 2008-495$ and $N^{\circ} 2013-1741$ ), the Swedish Research Council VR (grants $N^{\circ} 2008-4056$ and $N^{\circ} 2011-5768$ ), and the Carl Tryggers Foundation ( $\mathrm{N}^{\circ}$ CTS08:78). B.M.H. acknowledges funding from the Swedish Research Council VR (grant $\mathrm{N}^{\circ}$ 2011-6510). R.L. acknowledges funding from the European Commission Project INDOX ( ${ }^{\circ}$ FP7-KBBE-2013-7-613549), R.K. acknowledges the Austrian Science Fund (FWF, project $\mathrm{N}^{\circ} \mathrm{P} 25148-\mathrm{B} 20$ ) and D.K. thanks the Doctoral programme 'BioToP-Biomolecular Technology of Proteins' (FWF W1224). The research leading to these results has received funding from the European Community's Seventh Framework Programme (FP7/2007-2013) under BioStruct-X (grant agreement $\mathrm{N}^{\circ}$ 283570). The crystallographic work was facilitated by the Protein Science Facility at Karolinska Institutet/SciLifeLab (http://psf.ki.se). The SAXS work was conducted at the Advanced Light Source (ALS), a national user facility operated by Lawrence Berkeley National Laboratory on behalf of the Department of Energy, Office of Basic Energy Sciences, through the Integrated Diffraction Analysis Technologies (IDAT) programme, supported by DOE Office of Biological and Environmental Research, and additional support comes from the National Institute of Health project MINOS (R01GM105404); and at the MAX II SAXS beamline I911-SAXS at MAX IV Laboratory, Lund, Sweden. For automated docking using HADDOCK we acknowledge the use of web portals, computing and storage facilities made available through the WeNMR project (European FP7 e-Infrastructure grant, contract no. 261572, www.wenmr.eu), supported by the European Grid Initiative (EGI) through the national GRID Initiatives of Belgium, France, Italy, Germany, the Netherlands, Poland, Portugal, Spain, UK, South Africa, Malaysia, Taiwan, the Latin America GRID infrastructure via the Gisela project, the International Desktop Grid Federation (IDGF) with its volunteers and the US Open Science Grid (OSG).

\section{Author contributions}

C.S. and D.K. produced the $N c \mathrm{CDH}, M t \mathrm{CDH}$ and $M t \mathrm{CDH}$ variants; C.D. designed the $M t \mathrm{CDH}$ variants; R.K. cloned and produced $\mathrm{NcLPMO}_{9 \mathrm{~F}}$; T.C.T crystallized $M t \mathrm{CDH}$, $\mathrm{NcCDH}$ and $\mathrm{MtCYT}$; T.C.T. and C.D. determined, refined and analysed the structures of $M t C D H, N c C D H$ and $M t C Y T$; R.G. crystallized $N c L P M O_{9 F}$; R.G. and T.C.T. determined the structure of $N_{c L P M O}$; $;$ R.G. and C.D. refined the structure of $N c L P M O_{9 F}$; C.D. performed automated docking with HADDOCK of NcCDH and NcLPMO. B.M.H determined the crystal structure of $\mathrm{MtDH}$, collected the SAXS data for $\mathrm{NcCDH}$ and analysed the SAXS data for $M t \mathrm{CDH}$ and $\mathrm{NcCDH}$; C.D. refined the $M t \mathrm{DH}$ structure, and determined and refined the structure of $M t \mathrm{DH}-\mathrm{CBLM}$; D.K. performed rapid kinetics experiments; R.L. and C.D. supervised the work; B.M.H., D.H., R.L. and C.D. designed research, analysed data and wrote the manuscript.

\section{Additional information}

Accession codes. Atomic coordinates and structure factor amplitudes have been deposited with the Protein Data Bank (www.rcsb.org) under accession codes 4QI3 $(M t C Y T), 4 \mathrm{QI} 4(\mathrm{MtDH}), 4 \mathrm{QI5}(\mathrm{MtDH}-\mathrm{CBLM}), 4 \mathrm{QI} 6(\mathrm{MtCDH}), 4 \mathrm{QI} 7(\mathrm{NcCDH})$ and $4 \mathrm{QI8}\left(\mathrm{NcLPMO}_{9 \mathrm{~F}}\right)$.

Supplementary Information accompanies this paper at http://www.nature.com/ naturecommunications

Competing financial interests: The authors declare no competing financial interests

Reprints and permission information is available online at http://npg.nature.com/ reprintsandpermissions/

How to cite this article: Tan, T.-C. et al. Structural basis for cellobiose dehydrogenase action during oxidative cellulose degradation. Nat. Commun. 6:7542 doi: $10.1038 /$ ncomms8542 (2015).

cc (i) This work is licensed under a Creative Commons Attribution 4.0 cc International License. The images or other third party material in this article are included in the article's Creative Commons license, unless indicated otherwise in the credit line; if the material is not included under the Creative Commons license, users will need to obtain permission from the license holder to reproduce the material. To view a copy of this license, visit http://creativecommons.org/licenses/by/4.0/ 